\title{
Post-syntactic movement and the Old Irish Verb
}

\author{
David Adger \\ Queen Mary, University of London
}

May 2005

\begin{abstract}
The placement of second position clitics has been analysed as involving syntactic movement, morphological transpositions, or prosodic inversion. This paper argues that a syntactic treatment of the Old Irish verbal complex is untenable and that facts about allomorphy and phonological phrasing preclude a prosodic inversion analysis. I show how application of a morphological transposition operation (the Morphological Merger of Marantz 1988) not only to overt clitics in the language, but also to the functional head Force, provides a unified analysis of this highly intricate system.
\end{abstract}

\section{Introduction}

The positioning ${ }^{1}$ of certain clitic like elements in clause structure has often been argued to be determined by an interaction between syntax and phonology (Halpern 1995, Anderson 1993, Roberts 2000 among many others). Typically, the clitic is assumed to reach its final syntactic position as the result of a syntactic movement operation followed, in the Spellout component, by a prosodic operation which affects the linearisation of the clitic with respect to other material. An alternative (Marantz 1988, Embick and Noyer 2001) is that clitics may, be positioned by a purely morphological operation, which reorganises the linear relationships between $\mathrm{X}^{0}$ elements. Both accounts have the following schematic form, where the syntax delivers the structure to the left of the arrow, which is then modified by some post-syntactic operation to give the structure to the right of the arrow:

$$
\text { Clitic } \mathrm{X} \rightarrow \mathrm{X}+\text { Clitic }
$$

The prosodic account claims that the inversion is triggered by a prosodic property of the clitic (it has a prosodic subcategorization frame, requiring an element of a particular phonological status to its left). The morphological account rather makes reference to a morphological property of the clitic (it is a word-level suffix, rather than a prefix).

There is, of course, another possibility, which is that the syntax delivers the structure to the right of the arrow directly. This paper argues that this syntactic approach is ultimately unable to explain the complexities of the Old Irish verbal complex. I further show that the post-syntactic operation that creates the inverted structure is morphological, rather than prosodic, in that it creates a structure which feeds later morphological alternations (allomorphy) and prosodic and phonological operations (stress placement, ellision, assimilation, etc.). This paper, then, provides further evidence for a post-syntactic, pre-prosodic movement operation (the Morphological Merger of Marantz 1988 and Embick and Noyer 2001.

The empirical focus of the paper is a set of complex interactions between syntax, morphology and prosody in the Old Irish verbal complex. In the next section, I lay out some basic syntactic 
assumptions about Old Irish clause structure, and outline the basic problem the verbal complex raises. I then show how a syntactic approach leads to a paradoxical situation, and how this paradox does not arise if one assumes some limited post-syntactic movement.

\section{The Old Irish Verbal System}

\subsection{Old Irish Clause Structure}

OI is a VSO language (see Thurneysen 1975, Watkins 1963). Current transformational theory provides a number of possible derivations for surface VSO order which all posit an underlying VP. The motivation for this VP constituent is primarily theoretical (stemming from constraints on binary branching and $\theta$-role assignment), but it appears to have the right empirical consequences across a wide range of cases (see Anderson and Chung 1977, Sproat 1985, McCloskey 1983 and the papers collected in Carnie and Guilfoyle 2000).

This section argues that the most plausible derivation for VSO structure in Old Irish is that proposed for Modern Irish by McCloskey in a series of papers (McCloskey 1983, McCloskey 1991, McCloskey 1996). The idea is that the underlying structure is one where the verb and the object form a constituent to the exclusion of the subject, with subsequent raising of the verb to a projection in the higher functional domain. This means that an Old Irish example like (2) has the structure indicated: ${ }^{2}$

$$
\begin{aligned}
& \text { Beoigidir } \left.\left[V P \text { in spirut }\left[V^{\prime}\langle\text { beoigidir }\rangle \text { in corp }\right]\right] \text { in fecht so }\right] \\
& \text { vivifies-[3s.PRES }] \text { the spirit } \quad \\
& \text { 'The spirit now vivifies the body.' }
\end{aligned}
$$

Here we see the (deponent) verb beoigidir, 'vivifies', marked with third person singular present tense morphology. It is followed by the subject in spirut, 'the spirit' and then the object, followed finally by a right adjoined adverbial. Adopting the viewpoint of the Minimalist Program (Chomsky 2000, Chomsky 2001), the verb and object are originally Merged together, and this is followed by Merge of the subject. This gives a binary branching structure. The verb then raises out of VP to some higher projection, giving a VSO structure on the surface (I ignore the position of the adjunct here):

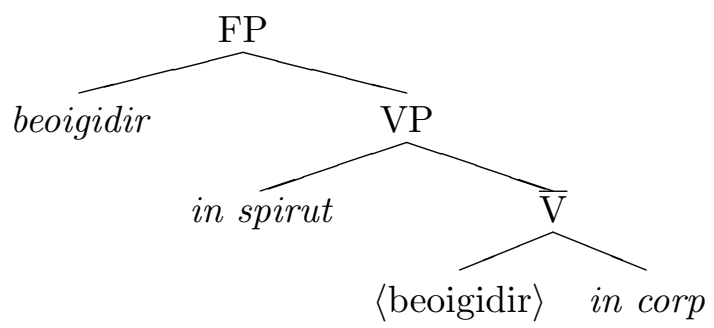

Evidence that these constructions are the result of verb raising from a base structure where the verb follows the subject can be constructed on the basis of examples similar to those used to make this argument for Modern Irish (see McCloskey 1983). The first kind of argument comes from examples where the verb is in a non-finite form. In such cases, rather than VS order, we find SV with nominative case available on the embedded subject: 
(4) Is bés leo-som [in daim do thúarcuin].

Cop custom with-them [the oxen-NOM prt thresh-VN]

'It is a custom with them that the oxen thresh.'

$\left(\mathrm{Wb} .10^{d} 6\right)$

Ní date leu [in comdiu do chrochad]

Neg agreeable to-them the lord-NOM prt crucify-VN

'It is not agreeable to them that the lord be crucified.'

(Wb. $\left.8^{a} 6\right)$

The verb here is in the verbal noun form (glossed as -VN) and bears no tense or agreement marking (see Jeffers 1978 for a discussion of the Old Irish verbal noun). If verb-raising is triggered by the requirement that the verb checks, or picks up, finite inflection (Pollock 1989, Chomsky 1993), then the SV order of these non-finite clauses becomes understandable. Non-finite clauses simply do not have the requisite functional material to trigger verb movement, and so the verb stays in its base position, adjacent to the object.

Backing up this argument for a VP constituent at some level of representation are facts which strongly suggest that the verbal noun combines with an object to form a single syntactic unit. Examples like the following show cases where the verbal noun followed by its object appears in the focus position of a cleft structure, indicating constituenthood.

(6) Is [oc precept soscéli] attó.

copula Asp preach-VN gospel that-be-[1s.PRES]

'I am preaching the gospel.'

(Wb. 21 $\left.{ }^{c} 19\right)$

(7) Is [do immarchor chóre] dotíagat

copula prt carry-VN peace that-come-[3P.PRES]

'It is to bring peace that they come.'

(Wb. $\left.5^{a} 5\right)$

Is [do thabairt dílgae] berid in claideb sin

copula prt give-VN punishment that-bear-[3S.PRES] the sword that

'It is for giving punishment that he bears that sword.'

(Wb. $\left.6^{a} 13\right)$

Putting these two sets of facts together, it appears that finite and non-finite clauses can receive a unified account if the verb initially combines with the object, forming a verbal constituent in both cases. The difference between the VS orders and the SV orders is that the verb raises past the subject in finite clauses but fails to do so in non-finite ones. This is precisely the kind of derivation assumed in most recent transformational studies of the word order of the descendents of Old Irish (see McCloskey 1983, McCloskey 1996, Bobaljik and Carnie 1996, Duffield 1995 for Modern Irish and Adger 1996 and Ramchand 1997 for Modern Scottish Gaelic).

Given these arguments, we will adopt the structure given in (2) for simple finite clauses in Old Irish.

VSO order is also found in embedded clauses. There are a number of ways of embedding clauses in Old Irish (see Ó hUiginn 1998 for discussion, sources and further examples). Embedding may have no formal marking, leading to a paratactic structure like (9):

$$
\begin{aligned}
& \text { Is airi asbersom [is dia ro-d-labrastar] } \\
& \text { therefore say-[3s.PRES] copula God PERF-3s.obj-speak-[3S.PAST] } \\
& \text { 'Therefore he says that it was God that had spoken it.' }
\end{aligned}
$$

(Ml. 126 10$)$

Alternatively, it may be signalled by a nasalization of the verb, marked by boldface $\mathbf{m}$ in the following example. In such cases we find a special relative inflection on the verb: 
... arnaro chretea mbiás ícc do hua dia.

... that-not-PERF believe be-[3s.REL] salvation to-him from God

'. . that he did not believe that his salvation would be from God.'

(Ml. 127 $7^{a}$ )

Another possibility is that the embedded clause is introduced by a complementizer (which, in this case, also triggers nasalization):

$$
\begin{aligned}
& \text {... ara mbé fer úaidib occa n-imchomét } \\
& \text {... that be-[3s.PRES.SUBJ] man from-them that them-would.guard } \\
& \text { '... that there should be a man from them to guard them.' }
\end{aligned}
$$

(Brechbetha 23)

In all of these cases verb-subject order is preserved even when the verb is embedded.

In addition to the Complementizer-VSO structure just seen for embedded clauses, we also find the same order of constituents in matrix clauses:

$$
\begin{aligned}
& \mathrm{Ni} \text { dénat firtu úili } \\
& \text { Neg work-[3P.PRES] miracles all } \\
& \text { 'Not all work miracles.' } \\
& \text { In coscram -ni } \\
& \text { Q destroy-[1P.PRES] -EMPH-1P } \\
& \text { 'Do we destroy?' }
\end{aligned}
$$$$
\text { (Wb. 12 } 20)
$$

I take the negative and question particles here to be types of complementizer, with the verb raising to the left edge of the inflectional domain of the cluase (or perhaps to the Fin position of Rizzi 1997). See section 4.4 for discussion.

\subsection{The Old Irish Verbal Cluster}

We now focus on a range of properties of the finite Old Irish verb which make it a challenging case from the perspective of modern generative theory. We will look at four properties: (i) the behavior of verbs which are compounded with a set of prepositional elements, traditionally termed preverbs; (ii) the kind of agreement inflection borne by the verb; (iii) the morphophonological relationships that hold or fail to hold between the verb and the pre-verbal particles (complementizers and preverbs); (iv) the position of clitic pronouns within the complex.

The interest of these four properties can be brought out by considering them first in the abstract. ${ }^{3}$ The Old Irish verbal cluster has the following schematic shape, where $[\mathrm{Y}+\mathrm{Z}+\mathrm{W}]$ contains the verb stem and $\mathrm{X}$ is a slot that hosts complementizers and preverbs:

$$
[\mathrm{X}] \cdot[\mathrm{Y}+\mathrm{Z}+\mathrm{W}]
$$

Phonologically, the two bracketed domains behave separately: $[\mathrm{Y}+\mathrm{Z}+\mathrm{W}]$ is a domain for a set of phonological processes which do not affect $\mathrm{X}$, and moreover, $\mathrm{Y}$ always bears main stress in this structure, while $\mathrm{X}$ is always unstressed. Syntactically, the position between the $\mathrm{X}$ and the remainder of the complex is that of object clitics, and, in archaic and poetic registers, it may also host entire phrases in a construction traditionally termed tmesis. Morphologically, in almost all circumstances, the presence versus absence of $\mathrm{X}$ triggers triggers different kinds of inflection on the verb. The descriptive question is how to capture all this, and we will see that answering this question leads to a set of interesting theoretical challenges. 


\subsubsection{Compound verbs}

As well as simple verbs like beoigidir (in (2)), Old Irish also had verbs which were constructed from a verbal stem with a set of preceding preposition-like elements, traditionally termed the preverbs (there need only be one preverb). Preverbs compound with stems to give rise to, sometimes unpredictable meaning shifts. For example, the verb berid, 'carries' combines with the preverb as, 'out' to give the compound verb as-beir, 'say'. Some verbs have a complex of preverbs, e.g. ga(i)r-, 'call' gives to-ga(i)r-, 'summon', for-cum-ga(i)r-, 'command', to-ar(e)-in-ga(i)r-, 'promise' etc. (see McCone 1997). I will gloss preverbs simply as PV, with the semantic force of the preverb expressed in the gloss of the verb stem. Such verbal forms are known as compound verbs.

Just like simple verbs, compound verbs appear in first position in finite sentences.

$$
\begin{array}{ll}
\text { As-ru-bart día friu-som ara celebartis a sollumnu. } \\
\text { PV-Perf-carry-[3s.PRES] god to.them that celebrate-[3P.PRES.SUBJ] his feasts }
\end{array}
$$

'God has said to them that they should celebrate his feasts.'

(Ml. $\left.102^{d} 3\right)$

In this example, the compound verb as-beir, 'say' appears in sentence initial position (with an extra preverb, ro/ru, signifying perfectivity). Compound verbs also appear clause initially in embedded finite clauses:

$$
\begin{aligned}
& \text {... are nind-arbe analchi óod. } \\
& \text {... that PV-banish-[3s.PRES.SUBJ] vices from-him } \\
& \text { '... that he banish from him his vices.' }
\end{aligned}
$$

In non-finite clauses, we find compound verbs in post-subject position, just as we saw for simple verbs.

$$
\begin{aligned}
& \text { Is bés leo-som [in daim do thú-arcuin] } \\
& \text { Cop custom with-them [the oxen-NOM prt PV-thresh] }
\end{aligned}
$$

'It is a custom with them that the oxen thresh.'

This last example is especially interesting. If we adopt the view argued for above, that it is finite tense which triggers movement of the verb, then the fact that the preverb and the verb appear after the subject in the subordinate clause here strongly suggests that the preverb and the verb stem are merged together before any further movements take place.

Compound verbs, then, syntactically behave the same as simple verbs, appearing in initial position in matrix and embedded finite clauses, and in final position in certain non-finite clauses.

There are a number of ways of implementing this idea: the preverb could be compounded with the verb either directly or it could merge with some projection of the verb with subsequent verb raising to form the compound. These two possibilities look as follows (see Carnie, Harley, and Pyatt 2000):

$$
\begin{aligned}
& {\left[{ }_{V P}\left[{ }_{V} \mathrm{PV} \mathrm{V}\right] \mathrm{DP}\right]} \\
& {\left[P V P\left[P V \mathrm{PV} \mathrm{V}_{i}\right]\left[{ }_{V P} \mathrm{t}_{i} \mathrm{DP}\right]\right]}
\end{aligned}
$$

In (18), the PV compounds directly with the verb stem and the whole structure is a projection of the verb. This new verb takes a DP object to which it assigns an appropriate $\theta$-role. In (19), we have a shell structure, somewhat similar to that propsed by Larson (1987), and developed by Pesetsky (1995) among others. The PV here merges with the projection of the VP, and then the verb raises and (right) adjoins to the PV. For this kind of approach, we would assume that the 
object is interpreted with an appropriate $\theta$-role because of the position in which it sits in the whole construction, as in the system of Hale and Keyser (1993). An alternative, which would seek to collapse these structures with Germanic particle verb constructions, would be to take the preverbs to be complements of the verb, which head raise and adjoin to $\mathrm{V}$, essentially resulting in a structure similar to (18):

$$
\left[{ }_{V}\left[{ }_{V} \mathrm{PV} \mathrm{V}\right]\langle\mathrm{PV}\rangle \mathrm{DP}\right]
$$

For the purposes of this paper, the exact derivation of compound verbs will not be crucial beyond the following two conclusions: (i) PVs Merge with the verb early on in the derivation (as is shown by their position in non-finite clauses where the verb has not raised), and (ii) the PV and V may form a complex head before verb raising to $\mathrm{T}$, since $\mathrm{PV}$ and $\mathrm{V}$ raise to $\mathrm{T}$ as a unit.

We have seen that compound and simple verbs have a range of syntactic commonalities; however, the following sections show that there is actually a crucial difference between compound and simple verbs: the initial preverb in a compound verb can be shown to behave like a complementizer in certain circumstances: that is, in our schema $\mathrm{X}$. $[\mathrm{Y}+\mathrm{Z}+\mathrm{W}], \mathrm{X}$ may be either a complementizer or the initial preverb of a compound verb. As we will see, it is this that raises the challenge for a purely syntactic account of the Old Irish verbal complex. The next few subsections show how this special behavior plays out in phonology, morphology and syntax.

\subsubsection{Phonological peculiarities}

The first fact to note is that simple and compound verbs display different behaviour with respect to stress placement. Stress in Old Irish is in general word initial (see Thurneysen 1975 for detailed argument and exemplification). I mark stress here by placing the stressed syllable in small capitals.

$$
\begin{aligned}
& \text { FAIRsingmenmaige } \\
& \text { 'magnanimity' (GOI 36) }
\end{aligned}
$$

Simple finite verbs conform to this constraint:

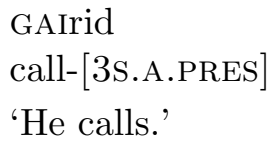

'He calls.'

(McCone 1997, p2)

Compound verbs also fit this pattern, when they occur after a certain set of complementizer-like elements (traditionally called conjunct particles):

$$
\begin{aligned}
& \text { ní -FO -dmat } \\
& \text { Neg -PV -endure-[3P.C.PRES] } \\
& \text { 'They do not endure.' } \\
& \text { ara -FU -lsam } \\
& \text { that -PV -support-[1P.C.PRES.SUBJ] } \\
& \text { 'so that we may support' }
\end{aligned}
$$

However, compound verbs when not preceded by a conjunct particle do not conform to the usual stress pattern. These verbs are stressed not on the first syllable, as one might expect, but rather on the first syllable after the first preverb: ${ }^{4}$ 
do- MOIniur

PV- think-[1S.C.PRES]

'I think.'

(GOI 37)

do -FOR -magar

PV -PV -increase-[3s.C.PRES.PASS]

'It is increased.'

(GOI 37)

As can be seen here, the first syllable after the first preverb is stressed, whether it is another preverb (26), or the first syllable of the root $(25) .^{5}$

It appears, then, that the first preverb of an initial compound verb, on the one hand, and conjunct particles, on the other, are grouped into the same class. Word stress on a finite verb is assigned to the syllable immediately following an element of this class, unless there is no such element, in which case it is assigned to the first syllable of the word. One might imagine, then, that the first preverb is somehow "set off" from the rest of a compound verb, if that verb is in initial position (i.e. not preceded by a conjunct particle). This is the first case which instantiates our abstract structure:

$$
\mathrm{X} \cdot[\mathrm{Y}+\mathrm{Z}+\mathrm{W}]
$$

Here $\mathrm{X}$ is either a conjunct particle or the first preverb. $\mathrm{Y}$ is either a preverb, or the verb root, stressed in either case.

This structural conclusion is backed up by the observation that the rightmost bracketed structure in (27) is a domain for phonological processes which exclude X. I give some examples below, but see McCloskey (1978) and McCone (1997) for extensive discussion:
(a) Vowel elision:
(b) Consonant assimilation:

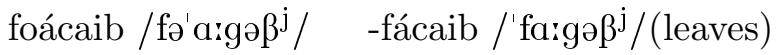
(c) Lenition (f lenites to 0):
adcobra /ad'kəbrə/ -accobra /'akəbrə/(sues)
(d) Consonant palatalization:
fofera /fə'f frr $^{\mathrm{j}}$ ə/
-foirea /'for ${ }^{\mathrm{j}} \partial /$ (causes)
doic $/ \mathrm{d}^{\prime} \mathrm{ik}^{\mathrm{j}} /$
-tic $/ \mathrm{t}^{\mathrm{j}} \mathrm{ik}^{\mathrm{j}} /$ (comes)

If we focus on the example of elision given in (a), we can see that after a conjunct particle (signalled by the dash) elision of phonetic schwa (which is underlyingly phonological $a$ and orthographic $o$ ) takes place before a following vowel; however, when the verb is in strictly initial position, this does not happen. In (b) we see consonant assimilation between preverb and verb blocked when the verb is initial. In (c), we see the preverb fo causing lenition of the following $f$ to zero when it follows a conjunct particle. However, when the verb is initial, no lenition takes place. Finally, in (d) schwa is deleted, the high vowel causes palatalization of the dental, and the dental looses its voiced status. In all these cases, a phonological process which would usually include the preverb is blocked when that preverb is in initial position.

\subsubsection{Morphological peculiarities}

The second property of note is that simple and compound finite verbs inflect differently. Simple verbs in initial position in matrix clauses take a set of agreement suffixes traditionally termed absolute inflection, while compound verbs in the same position are inflected with a different set of suffixes, traditionally termed conjunct inflection. This distinction is neutralised in favour of conjunct inflection in other contexts. Example (2), repeated here as (29), is a simple verb in initial position in a matrix clause, and hence bears absolute inflection: 
On the other hand, the matrix verb in (15) (repeated in (30)), being compound, bears conjunct inflection:

$$
\begin{array}{ll}
\text { As-ru-bart día friu-som ara celebartis a sollumnu. } \\
\text { PV-Perf-carry-[3s.PRES] god to.them that celebrate-[3P.PRES.SUBJ] his feasts }
\end{array}
$$

'God has said to them that they should celebrate his feasts.' [A.] ${ }^{6}$

From now on, I will mark conjunct inflection with a [C.] in the gloss, and absolute with an

A present paradigm for berid, 'carries', showing the difference between conjunct and absolute morphology, is as follows:

$\begin{array}{lll} & \text { Absolute } & \text { Conjunct } \\ 1 \text { singular } & \text { biru } & \text {-biur } \\ 2 \text { singular } & \text { biri } & \text {-bir } \\ 3 \text { singular } & \text { berid } & \text {-beir } \\ 1 \text { plural } & \text { bermai } & \text {-beram } \\ 2 \text { plural } & \text { beirthe } & \text {-berid } \\ 3 \text { plural } & \text { berait } & \text {-berat }\end{array}$

Since the conjunct forms are used with a compound verb like as-beir, 'says', they are marked with a slot (before the dash) for the preverb(s).

As well as appearing with compound verbs, conjunct inflection also occurs when the verb is preceded by the conjunct particles mentioned in the last section:

$\mathrm{Ni}$ dénat firtu úili.

Neg work-[3P.C.PRES] miracles all

'Not all work miracles.'

(Wb. $\left.12^{b} 20\right)$

No-scarinn friu.

Asp-separate-[1s.C.IMPF] against-them

'I was not separating from them.'

(Wb. $\left.24^{a} 4\right)$

(34) No-m.ísligur.

PV-me-abase-[1s.C.PRES]

'I abase myself.'

(Wb. $\left.17^{d} 22\right)$

As can be seen from the glosses, in each case the simple verb takes conjunct rather than absolute agreement. The aspectual particle in (33) appears where there is no other preverb in the imperfect. Likewise the dummy particle in (34) appears to support the clitic when there is no other preverb (see below). Perhaps these two (homophonous) particles can be unified, but we keep them separate for clarity here.

Turning now to embedded clauses which are introduced by complementizers, it turns out that here again we find conjunct inflection: 


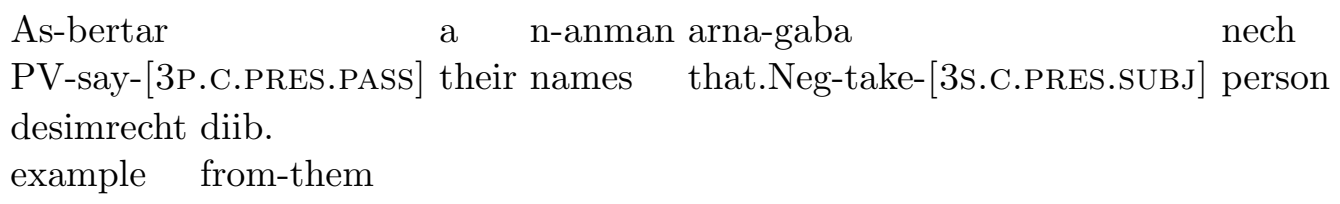

'Their names are mentioned so that no one may take example from them.'

This then is the second instantiation of our abstract schema:

$$
\mathrm{X} \cdot[\mathrm{Y}+\mathrm{Z}+\mathrm{W}]
$$

If $\mathrm{X}$ is a preverb, or a conjunct particle (whether matrix or embedded), the verb inflects in its conjunct form. If $\mathrm{X}$ is absent, the verb is absolute. ${ }^{7}$

This broad conclusion is also made in the philological literature. Watkins (1963) considers complementizers and negation to be in the same class as preverbs, so that the verbal complex consists of a number of preverbal elements and then the verb stem (we ignore clitics for the moment, but see below). Isaac (1993) also argues that conjunct particles and preverbs are in the same class, but assumes a distinction between aspectual and non-aspectual preverbs (see also McCone 1979). Isaac argues that the preverbs are positioned to the left of the verb itself on the basis of a functional principle which places light constituents first. A number of historical explanations for this pattern have been put forward (see the references above, and McCone 1982 and references therein). In this paper we are concerned with what the analysis of this data teaches us about the structure of the spellout component of the grammar and so we will be concerned with the system from a synchronic perspective only.

\subsubsection{Syntax: Clitic Placement}

Old Irish object pronouns behave like clitics in that they must be incorporated in some fashion into a host. There are two ways in which this happens, giving rise to a traditional distinction between suffixed pronouns and infixed pronouns. Suffixed pronouns are fairly restricted in their distribution. They occur attached to only absolute marked verbs, and, furthermore, the verb must be third person (see Breatnach 1977 for discussion).

$$
\begin{aligned}
& \text { Comallaid -i. } \\
& \text { fulfil-[3s.A.PRES] -3s.masc } \\
& \text { 'He fulfils it.' } \\
& \text { It -ius. } \\
& \text { eat-[3S.A.PRES] -3.s.fem }
\end{aligned}
$$

'He eats it.'

(Ml. $\left.102^{a} 15\right)$

Furthermore, the $\phi$-feature specification of the suffixed pronouns is highly restricted. They tend to be third person, unless occuring in a possessive dative structure with the third singular of the verb 'be':

$$
\begin{aligned}
& \text { táth -ut } \\
& \text { be-[3s.A.PREs] -2s } \\
& \text { 'you have' }
\end{aligned}
$$

In contrast, when there is a conjunct particle or a preverb, then this serves as a host for the object pronoun. The pronoun infixes between the conjunct particle or initial preverb and the rest 
of the verb stem:

$$
\begin{aligned}
& \text { Imm -us -(n)dích. } \\
& \text { PV -3pl -protect-[3s.C.PRES] }
\end{aligned}
$$

'He protects them'

(41) Ní -s -(n)im-dich.

Neg -3pl -PV-protect-[3s.C.PRES]

'He does not protect them.'

(McCone 1997, p11)

The pronoun appears attached between the preverb and the verb stem in (40), and between the conjunct particle and the preverb in (41). Unlike suffixed pronouns, infixed pronouns appear freely regardless of their $\phi$-feature composition or of the $\phi$-features on the inflection of the verb:

$$
\begin{aligned}
& \text { Ar -ut -neithius. } \\
& \text { PV -2s -await-[1s.C.PAST] } \\
& \text { 'I waited for you.' }
\end{aligned}
$$

There is clearly one ommission in the description outlined so far: what happens to object pronouns that occur with unembedded simple verbs, but which are not third person; such pronouns need to encliticize to something, but I stated above that they do not generally suffix to the verb. In such cases a special dummy preverb is inserted. We met this situation already in (34), repeated here:

$$
\begin{aligned}
& \text { No -m.ísligur. } \\
& \text { PV -me-abase-[1s.C.PRES] } \\
& \text { 'I abase myself.' }
\end{aligned}
$$

$$
\begin{aligned}
& \text { No -s -comalnamar. } \\
& \text { PV -3pl -fulfil-[1PL.C.PREs] } \\
& \text { 'We fulfil them.' }
\end{aligned}
$$

Once again we see that the initial preverb of a compound verb and a conjunct particle (whether it occurs with a simple or compound verb) behave alike: the infixed pronoun in both cases appears immediately following this element, in the position marked with a period in our schema:

$$
\mathrm{X} \cdot[\mathrm{Y}+\mathrm{Z}+\mathrm{W}]
$$

In fact, the position of clitics with simple verbs provide us with another conclusion. When $\mathrm{X}$ is absent, that is, there is no preverb or conjunct particle, the clitic appears after the whole verbal complex. The simple verb, then, takes the place of $\mathrm{X}$ in our schema in this case.

We have now met a number of phenomena in the Old Irish verbal system which all motivate the idea that the first preverb of a compound verb in initial position and conjunct particles fit into the same class: absolute/conjunct inflection, stress placement, phonological domain phenomena and pronoun placement. The question to be tackled is how to provide a principled account of this.

\section{A Syntactic Approach}

The main concern of Carnie, Harley, and Pyatt (2000) (hence CHP) is to show that Old Irish clause structure involves both movement of the finite verb to $\mathrm{T}$ and movement of the verb to $\mathrm{C}$. 
The evidence for this comes from their analysis of the kinds of data discussed in section 2. They argue that in embedded clauses, and clauses containing conjunct particles, the verb raises to $\mathrm{T}$, while in matrix clauses without conjunct particles, the verb raises intially to $\mathrm{T}$ and then further to C. To motivate this secondary step of raising, they propose a constraint holding of Old Irish clause structure which ensures that the $\mathrm{C}$ position is always filled by material with a phonological matrix. I will abbreviate this constraint as FILL-C.

In a clause with an embedding complementizer, or other conjunct particle (such as negation or question particles), FILL-C is automatically satisfied, since these particles are themselves of category C. In such clauses, the finite verb raises just to T, and this is why VSO order is still seen in embedded structures (in contrast to V2 in Germanic). This basic clause structure holds for sentences with conjunct particles irrespective of whether the verb is simple or compound.

When there is no conjunct particle, and the verb is simple, then FILL-C requires the verb to raise from $\mathrm{T}$ to $\mathrm{C}$, and it is as a result of this that absolute morphology is found on the verb and that the object pronouns follow an absolute verb and precede or infix to a conjunct verb (see Adger 2000 for a related perspective).

CHP point out that if the initial preverb of a compound verb in a simple sentence is also in $\mathrm{C}$, then we can capture the kinds of commonalities between this preverb and conjunct particles discussed in the previous section. They therefore propose the following kinds of sentence structure for Old Irish:

\begin{tabular}{lllll} 
C & Adjoined to C & T & Subject & Object Position \\
\hline Conjunct Particle & (Object Pronoun) & V-CONJUnCT & Subject & (Object) \\
Conjunct Particle & (Object Pronoun) & PV+(PV)+V-CONJunCT & Subject & (Object) \\
PV & (Object Pronoun) & (PV)+V-COnJUnCT & Subject & (Object) \\
V-ABSOlute $_{i}$ & (Object Pronoun) & $\mathrm{t}_{i}$ & Subject & (Object)
\end{tabular}

\subsection{Problems of Derivation}

This kind of an analysis, which places the first preverb in the same syntactic position as the conjunct particles and the absolute verb raises an interesting question of derivation, when put together with the assumption (motivated in section 2.1) that preverbs are merged low down in the structure, either with the main verb, or with a projection of the main verb.

For concreteness, assume that the preverbs are merged as Larsonian VP shells above the main verb in a structure like the following:

$$
\left[{ }_{P V P}[P V \mathrm{PV} \mathrm{V}]\left[{ }_{V P}\langle\mathrm{~V}\rangle \mathrm{DP}\right]\right]
$$

This is the approach adopted by CHP, and it makes sense of the semantic link between the preverb and the verb, and also of the fact that certain preverbs appear to perform an aspectual function. However, if the root verb raises to T in order to explain the VSO order, and the first preverb raises to $\mathrm{C}$, to explain the distributional similarities between preverbs and conjunct particles, then we have a violation of the head movement constraint (HMC), since the verb must skip the base position of the preverb as it raises to $\mathrm{T}$, and the preverb must skip $\mathrm{T}$ on its way to $\mathrm{C}$. So a derivation of a compound verb in initial position will look as follows:

$$
\left[C P \text { Preverb }\left[T P \text { Verb }\left[{ }_{P V P} \text { Subject }\left[{ }_{P V^{\prime}}\langle\text { Preverb }\rangle\left[{ }_{V P}\langle\text { verb }\rangle \text { Object }\right]\right]\right]\right]\right]
$$


If movement is defined so that the extraction site is the position most local to the landing site (Chomsky 1995) then the derivation represented in (48) should be ruled out. The closest head to the $\mathrm{C}$ position is $\mathrm{T}$, and it is $\mathrm{T}$ that should therefore be attracted to $\mathrm{C}$. Similarly, the preverb, rather than the verb, should be attracted to $\mathrm{T}$, if the two do not form a single $\mathrm{X}^{0}$.

Note that the problem is not ameliorated if we adopt the alternative perspective that the preverb and the verb Merge before the object is Merged:

$$
\left[{ }_{V P}\left[{ }_{V} \mathrm{PV} \mathrm{V}\right] \mathrm{DP}\right]
$$

If we adopt this approach, and assume that the whole complex raises into $\mathrm{T}$, we would need to assume that the preverb then excorporates into C to maintain the CHP story (see Carnie, Harley, and Pyatt 1995 for a version of this approach):

$$
\left[C P [ C \mathrm { PV } _ { i } \mathrm { C } ] \left[{ }_{T P}\left[{ }_{T} \mathrm{~T}[P V\langle\mathrm{PV}\rangle \mathrm{V}] \mathrm{T}\right] \ldots\right.\right.
$$

This idea clearly gets the distributional facts. The preverb is in the same position as complementisers and negation (on the assumption that negation is generated in $\mathrm{C}$, or obligatorily moves there), and plausibly the excorporation movement is motivated by FILL-C. However, the movement operation here would not be not standard excorporation, but something much less well-understood.

The notion of excorporation derives from work by Rizzi and Roberts (1989) who argue, on the basis of the behaviour of the verbal complex in French, that movement into head position is of two types: adjunction and substitution. When movement is triggered by a morphological subcategorisation requirement, then the resulting configuration is a substitution configuration and the moved element is 'frozen' in place. If, however, the movement is to an adjunction site, then excorporation may take place and the moved head may move from the adjunction site to a higher position.

Unfortunately, on this kind of account extra stipulations must also be made to ensure that just the first preverb excorporates into $\mathrm{C}$, rather than the whole verbal complex moving to $\mathrm{C}$, or some other combination of preverbal material. This is especially the case in an analysis which motivates the excorporation movement on the basis of a FILL-C constraint. If $\mathrm{C}$ needs to be filled, then the least problematic movement is to move the whole complex under T. But this, of course, does not explain the distributional or prosodic facts discussed above.

\subsection{Deriving the morphology via head movement}

CHP provide an interesting alternative solution to the HMC problem in terms of Long Head Movement (LHM - see Rivero 1991, Rivero 1994, Roberts 1994, Borsley, Rivero, and Stephens 1996, Rivero 2000, Holloway-King 1997 and references within). Long Head Movement is a term coined to describe the process whereby a participle (or more rarely an auxiliary) moves across a number of intervening head positions into C. This phenomenon is well known from Slavic languages, some Romance languages, and appears to occur in Breton as well. In order to deal with the apparent HMC violations, proponents of LHM argue that head positions are split into two groups, analogous to the $\mathrm{A}$ and $\overline{\mathrm{A}}$ groups of XP positions. HMC is taken to reduce to a version of Relativised Minimality, which forbids relations between a head and its trace if there is an intervening head of the same type. In the case under discussion, the idea is that the $\mathrm{C}$ position is an $\overline{\mathrm{A}}$-head position in OI, and therefore movement to this position across $\mathrm{T}$ is allowed. This is because, in the resulting representation, the head in $\mathrm{C}$ binds its trace across an A-head position ( $\mathrm{T}$ ), but not across another $\bar{A}$-head position. Since there is no intervening head of the same type as C, the representation satisfies Relativised Minimality and is well-formed: 


$$
\left[{ }_{C P} \text { Preverb }\left[{ }_{T P} \text { Verb }\left[{ }_{v P} \text { Subject }\left[{ }_{v^{\prime}}\langle\text { Preverb }\rangle\left[{ }_{V P}\langle\text { Verb }\rangle \text { Object }\right]\right]\right]\right]\right]
$$

However, there is a range of problems with this account which make it unsatisfactory, some of which are noted by CHP. The first is that the putative movement of these Old Irish preverbs doesn't seem to behave like the well-understood cases of LHM at all. LHM generally moves non-finite (participial forms of) main verbs into first position, rather than particles associated with finite verbs. LHM appears to take place to license a tense feature in C (Rivero 2000); other ways of satisfying this tense feature are rather uniform across languages: movement of some XP to [Spec, $\mathrm{CP}]$ is sufficient, but nothing analogous to this occurs in OI. ${ }^{8}$

In addition, Rivero (2000) shows that languages which have LHM allow the licensing of the Tense feature in $\mathrm{C}$ to take place via the L-marking of the embedded $\mathrm{CP}$ by the higher verb, so that LHM does not generally take place in embedded contexts. Now it is true that, when there is a filled complementiser, the preverb does not raise to the $\mathrm{C}$ position, as we saw in example (16), repeated here.

$$
\begin{aligned}
& \text {... are nind-arbe analchi óod. } \\
& \text {... that PV-banish-[3s.c.PRES.SUBJ] vices from-him } \\
& \text { '... that he banish from him his vices.' }
\end{aligned}
$$

However, there are cases in OI where the preverb does occur in first position in embedded clauses. Recall that one strategy for embedding clauses in Old Irish involves nasalizing the embedded verb. Interestingly, if the embedded verb has an initial preverb, then the nasalisation takes place to the right of this preverb, as can be seen from the boldface $\mathbf{n}$ in (53).

$$
\begin{aligned}
& \text {... epert frissom rondbiad fáilte libsi } \\
& \text {... say-VN to-him PV-be-3s.c.PRES.SUBJ joy with-you } \\
& \text { '... to say to him that there would be joy with you.' }
\end{aligned}
$$

If movement of the preverb is indeed LHM, then it should be blocked in examples like (53), since the embedded clause is L-marked by the higher verb.

These arguments suggest that the putative preverb movement in Old Irish is rather different from standard cases of Long Head Movement, and would require an extension of the theories of LHM developed by Rivero and others.

However, I think that there are further reasons for rejecting a purely syntactic account, which have to do with the mechanics of the derivations.

Firstly, a derivation where $\mathrm{V}$ raises and adjoins to a preverb and then this complex head raises to $\mathrm{T}$ is well formed under this account:

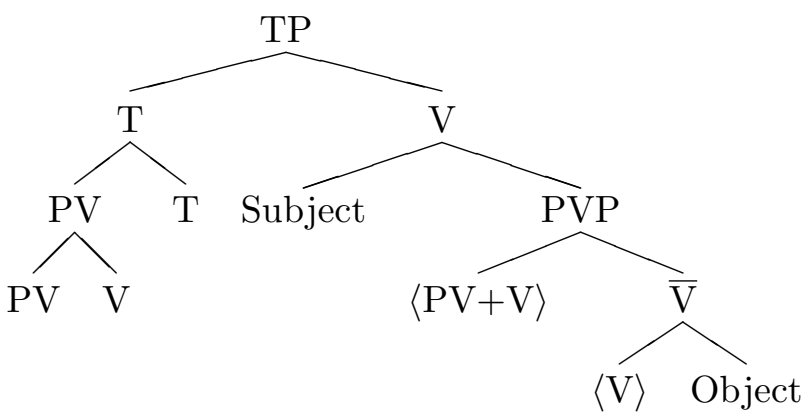


This seems to be correct, since, when $\mathrm{C}$ is filled by a complementizer, this is exactly the structure we want:

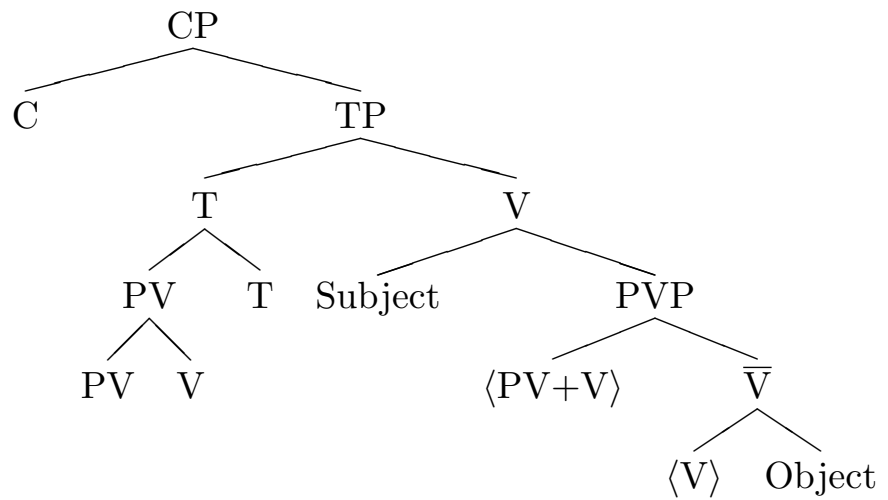

This is the structure for examples like (16), repeated here:

$$
\begin{aligned}
& \text {... are nind-arbe analchi óod. } \\
& \text {... that PV-banish-[3s.PRES.SUBJ] vices from-him } \\
& \text { '... that he banish from him his vices.' }
\end{aligned}
$$

(Thes. 2, 244.21)

Unfortunately, this now makes a prediction that we don't want: subsequent raising of the whole $\mathrm{T}$ complex to $\mathrm{C}$ would also satisfy FILL-C in the absence of an overt $\mathrm{C}$. This, however, does not give the required structure:

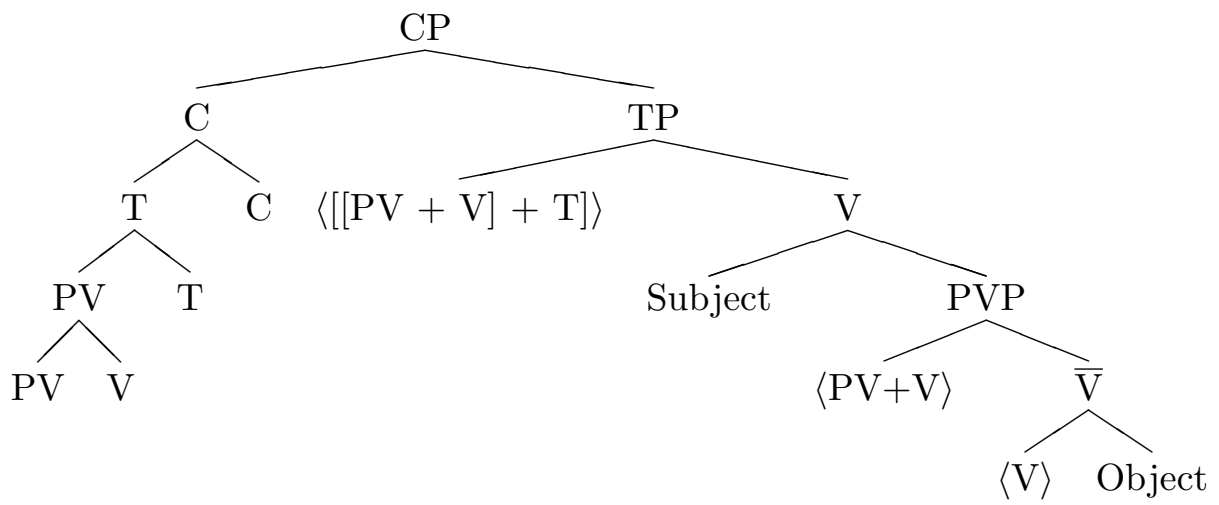

This structure would predict initial stress on the first preverb, absolute agreement and suffixed pronouns, contrary to fact. To maintain a CHP-style analysis, some mechanism to block this movement must be posited.

However, simple verbs do in fact raise to adjoin to empty $\mathrm{C}$, so we must allow $\mathrm{T}$ to raise to $\mathrm{C}$ if we are to capture that part of the analysis: 


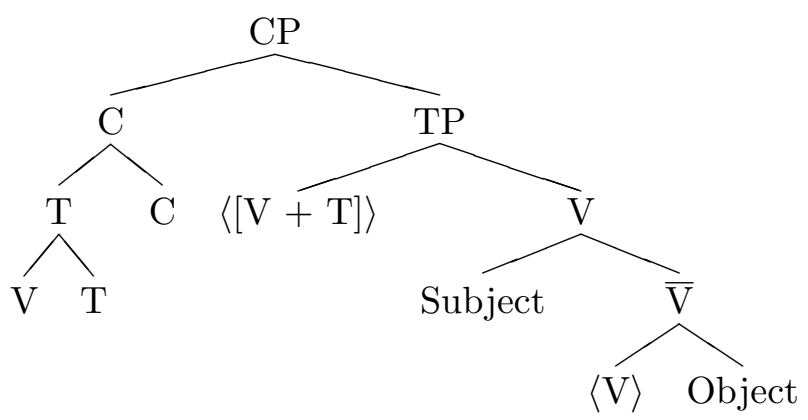

But now we are faced with a paradox: we need to block compound verbs from raising to $\mathrm{C}$, but allow simple verbs to do so. But this requires us to be able to distinguish between a compound verb that has raised to $\mathrm{T}$, and a simple verb that has raised to $\mathrm{T}$. Yet the movement operation attracts $\mathrm{T}$ to $\mathrm{C}$, and there is no obvious way that this operation can be made sensitive to the internal content of $\mathrm{T}$.

The dilemma is a real one. Imagine we say that there is a C which bears PV features. This $\mathrm{C}$ will be unable to attract a PV that has a verb adjoined, since this would be excorporation. However, there must also be a $\mathrm{C}$ which attracts a simple verb in $\mathrm{T}$. Even if we say that such a $\mathrm{C}$ attracts $\mathrm{V}$, and that $\mathrm{T}$ is just pied-piped, we have to ask the question, why this $\mathrm{C}$ cannot attract a compound verb in T. The only way I can see to do this, would be to have a filter which blocks a compound verb raising to C. Of course, such a filter just stipulates what we want to explain.

Even with this filter in place, there's still a problem. Imagine we have our C with PV features. It will attract a PV, but not $\mathrm{T}$. We also need a $\mathrm{C}$ to attract $\mathrm{T}$, though. So we need two empty C's: one with $\mathrm{T}$ features and one with PV features. But now we have more or less just stipulated the various orders: we have one empty $\mathrm{C}$ to force preverb raising; one empty $\mathrm{C}$ to force initial verb position, and we have stipulated categorial restrictions on these to ensure the right thing occurs in the right position. Moreover, we still need a filter to block compound verbs moving to C.

I think, then, that, although the surface outcome of the LHM analysis is undeniably attractive, LHM simply cannot be the mechanism which positions the elements of the OI verbal complex. ${ }^{9}$

\section{A post-syntactic movement account}

\subsection{Framework}

The proposal I would like to defend is couched within the organization of the Spellout systems envisaged by Marantz 1988 and Embick and Noyer 2001. These authors argue that the output of syntactic structures may be modified in various ways after syntax. Marantz proposes that syntactic structures may be rebracketted post-syntactically, and that this rebracketting allows affixation of one element to another. From this, he deduces a theory of clitics. We will appeal to this theory of clitics here to explain the curious properties of the Old Irish verbal system in general.

Let us take the structure of the Spellout System to be something like the following:

$$
\begin{aligned}
& \text { Syntax } \rightarrow \text { Morphological Labelling } \rightarrow \text { Morphological Merger } \rightarrow \text { Vocabulary Insertion } \rightarrow \\
& \text { Prosodic Labelling } \rightarrow \text { (Prosodic Inversion })
\end{aligned}
$$

Morphological Labelling simply marks elements as different kinds of $X^{0}$ s. Morphological Merger allows affixation of one element to another, and Vocabulary Insertion substitutes phonological for morphosyntactic features. Prosodic labelling is relevant for stress placement, while Prosodic 
Inversion is the prosodic analogue of Morphological Merger. Below, I'll briefly provide some details for each of these aspects of the Spellout Systam.

For Morphological Labelling, Embick and Noyer give the following definitions of Morphological Word and Morphological Sub-Word (p574):

(60) At the input to Morphology, a node $\mathrm{X}^{0}$ is a morphosyntactic word (MWd) iff $\mathrm{X}^{0}$ is the highest segment of an $\mathrm{X}^{0}$ not contained in another $\mathrm{X}^{0}$.

(61) A node $\mathrm{X}^{0}$ is a subword ( $\mathrm{Swd}$ ) if $\mathrm{X}^{0}$ is a terminal node and not an MWd.

What these definitions do is label sub- $\mathrm{X}^{0}$ terminals as subwords, and topmost $\mathrm{X}^{0} \mathrm{~s}$ as morphosyntactic words. The idea is that operations of the morphological component appeal to exactly these categories.

One of the main operations of this component is Morphological Merger. This replaces an adjacency relation between $\mathrm{X}$ and $\mathrm{Y}$ by affixing (the head of) $\mathrm{X}$ to (the head of) $\mathrm{Y}$. Embick and Noyer give two types of Merger: Lowering and Local Dislocation. Lowering essentially adjoins a head to the head of its complement, while Local Dislocation adjoins a head to another head to which it is strictly adjacent. Lowering, then, is fed by complementation, while Local Dislocation is fed by linear adjacency.

$$
\begin{aligned}
& \text { Lowering: }\left[X_{X} \mathrm{X}^{0} \ldots\left[\begin{array}{llll}
Y P & \ldots & \mathrm{Y} & \ldots
\end{array}\right]\right] \rightarrow[X P \\
& \text { Local Dislocation: }[\mathrm{X} *[\mathrm{Z} * \mathrm{Y}]] \rightarrow\left[Z_{Z^{0}} \mathrm{Z}+\mathrm{X}\right] *[\mathrm{Y}]
\end{aligned}
$$

In a Local Dislocation structure, the relationship of left adjacency of heads is converted into a relationship of adjunction. The interpretation of the $* \operatorname{symbol}$ in $[\mathrm{X} *[\mathrm{Z} * \mathrm{Y}]]$ is that $\mathrm{X}$ is left adjacent to $\mathrm{Z}$ which is left adjacent to $\mathrm{Y}$. In the Local Dislocated version, $\mathrm{Z}$ is still left adjacent to $\mathrm{Y}$ (since $\mathrm{Z}^{0}$ is) and the adjacency between $\mathrm{X}$ and $\mathrm{Z}$ is converted into an adjunction relation.

Both types of operation create adjunction structures which are linearized according to the properties of the vocabulary elements involved. Thus, they may be string vacuous, or allow a limited amount of inversion, if, for example, one of the elements is specified as being a suffix, or a prefix.

Embick and Noyer provide an analysis of Lithuanian reflexives to show how their system works. Lithuanian behaves similarly to Old Irish in having a second position clitic that can appear after verbs or after a preverb, if present:

$$
\begin{aligned}
& \text { a. Laikaũ 'I consider, maintain' } \\
& \text { b. } \quad \text { Laikaũ-si 'I get along' } \\
& \text { a. } \quad \text { iš-laikaũ 'I preserve, withstand' } \\
& \text { b. } \quad \text { iš-si-laikaũ 'I hold my stand' }
\end{aligned}
$$

Embick and Noyer propose to capture this as follows. They first assume that preverbs are adjoined to the verb and that this complex raises to T. The reflexive clitic is taken to be adjoined to the start of this complex: 


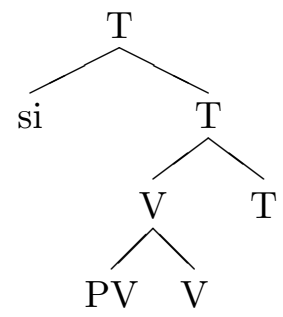

They then argue that $\mathrm{T}$ undergoes Local Dislocation with $\mathrm{V}$, string vacuously. This means that the relationship of adjacency between the $\mathrm{V}$ and $\mathrm{T}$ nodes is replaced by one of adjunction of $\mathrm{T}$ to $\mathrm{V}$ :

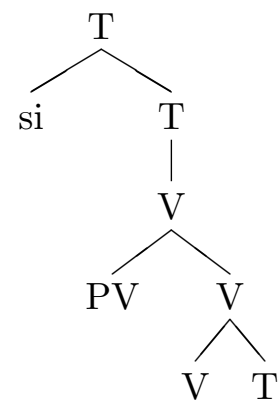

The reflexive clitic is left adjoined to the whole complex and is assumed to undergo Local Dislocation with the Preverb. It does this by exchanging its relationship of left adjacency with the preverb for one of right adjunction:

(68)

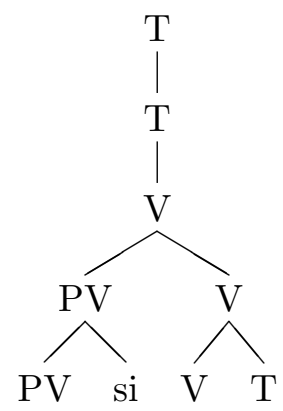

If there is no preverb, then the clitic locally dislocates with the $[\mathrm{V}+\mathrm{T}]$ complex. Embick and Noyer ensure this by taking the outcome of the local dislocation that moves $\mathrm{T}$ to $\mathrm{V}$ to create a single complex SWd, which is targeted by the next Local Dislocation operation: ${ }^{10}$

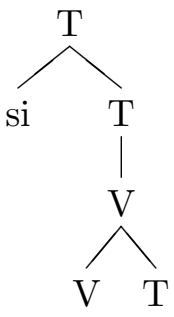




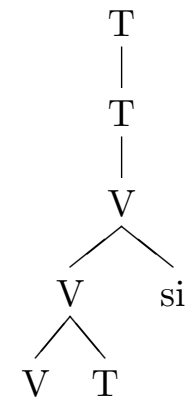

As is evident, the phenomenon in Lithuanian is reminiscent of the placement of Old Irish pronominal clitics.

Embick and Noyer make a further claim about Local Dislocation, which is that it is fed by Vocabulary Insertion, distinguishing it from Lowering, which feeds Vocabulary Insertion. Their approach, therefore, assumes a more detailed architecture:

$$
\begin{aligned}
& \text { Syntax } \rightarrow \text { Morphological Labelling } \rightarrow \text { Lowering } \rightarrow \text { Vocabulary Insertion } \rightarrow \text { Local Disloca- } \\
& \text { tion } \rightarrow \text { Prosodic Labelling } \rightarrow \text { Prosodic Inversion }
\end{aligned}
$$

We will see that the facts of Old Irish suggest that Local Dislocation in fact precedes Vocabulary Insertion, since it conditions allomorphy. This suggests that the more conservative picture in (59) above is correct.

\subsection{The proposal}

The analysis of Old Irish that I propose here adopts Rizzi's (1997) proposal that the C domain has a fine grained structure involving positions marking semantic Force, Topic and Focus, viz:

$$
[\text { Force } P \text { Force }[\text { TopP } \text { Top }[\text { FocP } \text { Foc }[\text { TopP } \text { Top }[\text { FinP } \text { Fin ... }
$$

I take Force to formally encode the embeddedness of the clause (perhaps best thought of semantically as related to the directness of the speaker's relation to the clause), rather than whether the clause is an imperative, a question, or negated. These other semantic functions are encoded lower down than Force (see, for example, Poletto 2000). I take Topic and Focus Projections to be present only when they are semantically required.

The proposal itself is the following:

$$
\text { Force is subcategorized to be enclitic to an } \mathrm{X}^{0} \text {. }
$$

The structure of the solution is as follows: in our original schema, $\mathrm{X}$ is syntactically preceded by a clitic Force. Given (73), Force will have to Locally Dislocate to the next $\mathrm{X}^{0}$ :

$$
\text { Force X Y Z W } \rightarrow[\mathrm{X}+\text { Force }] \mathrm{Y} \mathrm{Z} \mathrm{W}
$$

$\mathrm{X}$ can be a conjunct particle, or a preverb, or a simple verb. To deal with the phonological peculiarities noted above, it will suffice to make the phonological phrasing of the structure sensitive to the prosody of Force. I show how this works in the next subsection.

Force can also act as a conditioner for allomorphy of the verbal agreement suffixes. If $\mathrm{X}$ is a simple verb, then it is immediately followed by Force. The idea is that this provides an insertion 
context for allomorphy of agreement, causing absolute agreement to surface. The mechanisms and consequences of this are detailed in section 4.4.

Finally, in Rizzi's system, Force has a Topic position immediately to its right. Pronouns syntactically move to this position (see Roberts 2005 for a similar view of these pronouns), and then lower post-syntactically, accounting for their final position. This proposal also accounts for cases of tmesis and Bergin's Law constructions. This is dealt with in section 4.5.

\subsection{Phonology}

Recall that words are stressed at their left edge in general in Old Irish. Green (1997) proposes to capture this trochaic pattern by constructing a left headed foot at the left edge of the prosodic word; the lack of any kind of alternating stress on non-initial syllables motivates the idea that only the first part of the word is parsed into feet:

$$
\begin{aligned}
& \text { a. FAIRsingmenmaige } \\
& \text { 'magnanimity' (GOI 36) }
\end{aligned}
$$

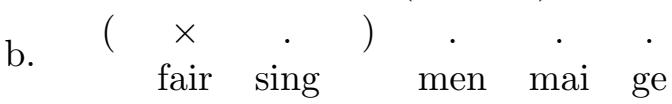

Accepting this basic idea, we then need to work out how the morpho-syntactic structure is related to the prosodic structure.

Classical views of the relation between syntactic and prosodic structure essentially map from aspects of the syntactic representation into prosodic categories. So, for example, Selkirk's (1986) End Based Mapping correlates the left (or right) edge of a syntactic category with the left (or right) edge of a prosodic one (a theory which has been more or less directly incorporated into Optimality Theoretic approaches). Selkirk (1995) argues that in languages which have pro-clitics, a constraint is in operation which aligns the left edges of prosodic words with the left edge of lexical words:

Align the left edge of every lexical word with the left edge of a prosodic word.

For example, in English, we have the following, with $\phi$ being the label for phonological phrase and $\omega$ the label for prosodic word:

$$
\left({ }_{\phi} \text { the }(\omega \text { examination })\right)
$$

This same constraint appears to be in operation in Old Irish, with definite articles etc. being unstressed proclitics to the noun (see Thurneysen 1975, p30).

Simple verbs also fall straightforwardly under this analysis (78), as do compound verbs which occur after a complementizer. Recall that these are stressed on the first preverb (79):

$$
\begin{aligned}
& \text { GAIrid } \\
& \text { call-[3s.A.PRES] } \\
& \text { 'He calls.' } \\
& \text { ara -FU -lsam } \\
& \text { that -PV -support-[1P.C.PRES.SUBJ] } \\
& \text { 'so that we may support' }
\end{aligned}
$$

(McCone 1997, p2)

In each case, the prosodic word is aligned with the lexical word (assuming that the [PV V] complex counts as the lexical word, for the purposes of the alignment constraints). 
The problem occurs with compound verbs in initial position. With these, the first preverb is treated as a proclitic, and stress appears after this proclitic:

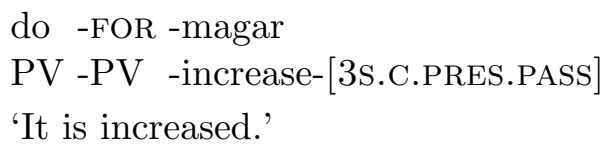

Here, the prosodic word is not aligned with the first preverb, but rather with the second. It appears, then, that we have to recognize the first preverb as being part of the lexical word in some cases, and not part of it in others.

The proposal outlined above allows us to resolve this apparent paradox straightforwardly. The structure that is prosodically parsed for an example like (80) is as follows:

$$
\text { PV+Force PV V }
$$

This would be given the following structure on alignment, assuming that the PV is part of the lexical word:

$$
(\omega \mathrm{PV}+\text { Force PV V }
$$

This would then lead to incorrect footing and stressing, since it would predict that the preverb should be footed and stressed.

However, Force is typically a category that marks the left edge of a phonological constituent larger than the prosodic word (either a phonological phrase, or an intonational phrase). Assume then an alignment constraint which aligns Force as follows (see, e.g. Szendroi 2001 for motivation for such a constraint):

Align the left edge of a phonological phrase (or perhaps an intonational phrase) with the right edge of Force.

This now gives us:

$$
\left({ } _ { \omega } \mathrm { PV } + \text { Force } \left({ }_{\phi} \mathrm{PV} \mathrm{V}\right.\right.
$$

However, there is a strict dominance relation between elements of the prosodic hierarchy (Selkirk 1995), which rules this structure out.

$$
\text { A phonological phrase cannot be contained within a prosodic word. }
$$

In OT terms, the only structure which satisfies (85) and (83), is one which is parsed as follows:

$$
\mathrm{PV}+\text { Force }{ }_{\phi}\left({ }_{\omega} \mathrm{PV} \mathrm{V}\right.
$$

This violates (76), which therefore must be taken to have a lower ranking. It is, however, exactly the structure we need: it predicts that the complex of the second preverb and the verb will be footed and initially stressed. Furthermore, if there is just one preverb, then it correctly predicts that the stress will fall on the verb root itself. ${ }^{11}$

This approach also captures the behavior of simple verbs on the assumption that prosodic words are closed at the right edge of their lexical word:

$$
\text { Align the right edge of a prosodic word with the right edge of the lexical word. }
$$

This gives us the following structure: 


$$
\left(\omega \mathrm{V}_{\omega}\right) \text { Force }(\phi \cdots
$$

This predicts that in the case of a simple verb, the verb is phrased as phonologically separate from the following subject. This is consistent with what little we know of the sentence prosody of Old Irish, since a following subject DP forms a phonological phrase of its own (hence its determiners etc. behaving like proclitics to $\mathrm{N}$, rather than enclitics to $\mathrm{V}) .{ }^{12}$

Finally, for cases where we have a conjunct particle in $\mathrm{C}$, we predict the following prosodic structures:

$$
\begin{aligned}
& \text { a. C+Force }\left(_{\phi}(\omega \mathrm{V}\right. \\
& \text { b. } \mathrm{C}+\text { Force }{ }_{\phi}\left({ }_{\omega} \mathrm{PV}\right. \text { V }
\end{aligned}
$$

This correctly captures the appearance of initial stress on a preverb (if one is present) and on the verb otherwise.

Note that we have now also created two separate domains for phonological processes in compound verbs, created by the boundary induced by Force. This explains why processes of ellision, assimilation and some lenition (that is, purely phonological lenition) are blocked between the initial element and the remainder of the verbal complex, in a compound verb.

\subsection{Morphology}

Recall that the crucial morphological fact to be accounted for is the difference between conjunct and absolute inflection. On the proposal defended here, this arises because Force, when it encliticises to a main verb, serves as a conditioner of allomorphy for inflection.

Within Distributed Morphology allomorphy is cashed out at Vocabulary Insertion. Vocabulary Insertion involves replacing morphosyntactic feature bundles with phonological structures. Each Vocabulary Item (VI) has the basic structure of (90) or (91):

$$
\begin{aligned}
& / \text { phon1 / } \mathrm{F} \\
& / \text { phon2 / } \mathrm{F} / \ldots \mathrm{G},
\end{aligned}
$$

In these schemas, $\mathrm{F}$ and $\mathrm{G}$ represent morphosyntactic feature bundles, and /phon/ a phonological structure. In (90), we see a schematic VI which instructs us to replace the feature bundle $\mathrm{F}$ with the phonology /phon1/, while in (91) we insert /phon2/ for F if F is in the context G.

VIs compete for insertion, so that more specific VIs are inserted in preference to less specific ones. A VI with a context specification is automatically more specific than one without, so if $\mathrm{F}$ is in the context $\mathrm{G}$, /phon2/ will be inserted rather than /phon1/. Competition also takes place between VIs which have feature bundles that stand in subset relations, but these will not concern us here.

Once the phonological matrices have been inserted, phonological rules apply to derive the surface representation, which interfaces with the Articulatory/Perceptual systems.

With this in mind, take a simple verb in Old Irish in initial position. I will assume for concreteness that the verb has syntactically moved to T in such cases. Adopting Rizzi's system, this means that Fin is syntactically absent (see Starke 2004 for argument that categories in the functional sequence are absent when they receive a default interpretation). ${ }^{13}$ In the simplest examples, there is nothing in Focus or in Top, so we simply have the following structure, where Force is left adjacent to $\mathrm{T}$ and $\mathrm{V}$, and $\mathrm{V}$ is left adjacent to $\mathrm{T}$ :

$$
\text { Force }\left[\mathrm { TP } \left[T^{0} \mathrm{~V} \text { T] } \ldots\right.\right.
$$


We will adopt Embick and Noyer's proposal that T string vacuously Locally Dislocates to V:

$$
\text { Force } *\left[T^{0} \mathrm{~V} * \mathrm{~T}\right] \ldots \rightarrow \text { Force } *\left[T^{0}\left[{ }_{V^{0}} \mathrm{~V}+\mathrm{T}\right]\right]
$$

On our proposal, Force Locally Dislocates to the next $\mathrm{X}^{0}$. Since, after Local Dislocation of $\mathrm{T}$ to $\mathrm{V}$, these terminals are part of a complex $\mathrm{X}^{0}$, Force appears to the right of this complex head, just as in the Lithuanian case discussed above:

$$
\left[\left[\left[V^{0} \mathrm{~V}+\mathrm{T}\right]+\text { Force }\right]\right] \ldots
$$

We now insert Vocabulary Items for the various heads. For $\mathrm{T}$ we have items which schematically look as follows:

$$
\begin{aligned}
& \text { / conjunct } / \leftrightarrow \mathrm{T} \\
& \text { / absolute / } \mathrm{T} / \text { _Force }
\end{aligned}
$$

This now captures the generalization that absolute forms only appear when Force has cliticized to $\mathrm{T}^{0}$. This will only happen when there is no other element which precedes $\mathrm{T}^{0}$ to which Force can encliticize, capturing the generalization that absolute forms appear when the verb is in absolute initial position.

Turning to the cases where the verb is not in strictly initial position, let us take a compound verb in initial position:

$$
\begin{array}{ll}
\text { As-ru-bart día friu-som ara celebartis a sollumnu. } \\
\text { PV-Perf-carry-[3s.PREs] god to.them that celebrate-[3P.PRES.SUBJ] his feasts }
\end{array}
$$

'God has said to them that they should celebrate his feasts.'

(Ml. $\left.102^{d} 3\right)$

The structure delivered by the syntax is as follows:

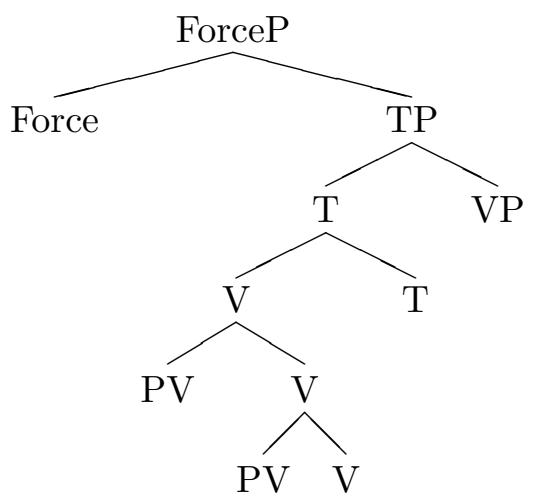

Local Dislocation moves $\mathrm{T}$ to adjoin to V. It then moves Force to adjoin to the first PV that it is left adjacent to: 


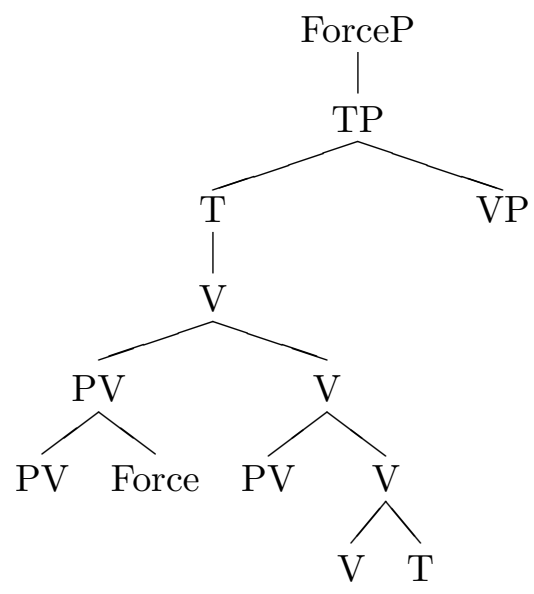

Now, when we come to insert the inflectional morphology for $\mathrm{T}$, the only possibility is conjunct inflection, capturing the correlation between such inflection and compound verbs.

The same outcome is predicted when we have a verb (either simple or compound) preceded by a conjunct particle. As mentioned above, negation in Old Irish is marked by an element in the complementizer system:

$$
\begin{aligned}
& \text { Ni dénat firtu úili. } \\
& \text { Neg PV-work-[3P.C.PREs] miracles all } \\
& \text { 'Not all work miracles.' }
\end{aligned}
$$

Schematically, we have:

$$
\text { Force } * \mathrm{Neg} *\left[V^{0} \mathrm{~V} \mathrm{~T}\right] \ldots
$$

Force encliticises to Neg, giving:

$$
[\text { Neg Neg+Force }]\left[V^{0} \mathrm{~V} \text { T] } \ldots\right.
$$

Now, when we come to insert the morphology for $\mathrm{T}$, we correctly predict conjunct agreement, since Force is not available to condition allomorphy of $\mathrm{T}$.

This account can also extend to other cases where absolute appears. Recall that the preverbal element ma/má co-occurs with absolute inflection (see Newton 2002 for some discussion):

$$
\begin{aligned}
& \text { Má beid ní di rúnaib do-théi ar menmuin ind fir } \ldots \\
& \text { if be-[3s.A.PRES.SUBJ] anything of mysteries go-3s.SUBJ before mind the man ... } \\
& \text { 'If it might be that any of the mysteries should come before the mind of man ...' } \\
& \text { (Wb. } 13^{a} 12 \text { ) }
\end{aligned}
$$

However, ma does not act as a host for second position clitic pronouns (see Newton 2002), so there is no expectation that it should act as a host for second position clitic Force. Presumably it is too high up in the structure to be parsed as part of the same complex, or the enclitic nature of Force is such that it needs to attach to an $\mathrm{X}^{0}$, and $m a$ is a syntactically complex XP. Absolute inflection on a simple verb can be correctly captured:

$$
[X P \text { ma }] *{ }_{\text {Force } P} \text { Force } *[\mathrm{~V}+\mathrm{T}] \ldots \rightarrow[X P \text { ma }] *\left[{ }_{\text {Force } P}\left[T^{0}[\mathrm{~V}+\mathrm{T}]+\text { Force }\right] \ldots\right.
$$

There is one more type of inflection in the Old Irish verb, which we met briefly above: relative inflection. This occurs when the simple verb heads a relative clause of some sort: 
Bid húathad creitfes.

be-[3s.A.FUT] few believe-[3s.R.PRES]

'It will be a small number that believe.'

(Wb. $\left.4^{d} 5\right)$

Here the verb inflects with the special relative form (glossed with $[\mathrm{R}]$ ). We can capture this with the following kind of schema for vocabulary items:

$$
\text { / relative / } \leftrightarrow \mathrm{T} / \text { _Force[Rel] }
$$

Now this makes a further interesting prediction. Old Irish relative clauses are obligatorily marked by lenition when the verb is compound and the subject has been extracted. ${ }^{14}$ Strikingly, the lenition (marked in bold) appears after the first preverb:

$$
\begin{aligned}
& \text {... din gním for-chomnaccuir. } \\
& \text {...to-the deed PV-happen-[3s.C.PAST] } \\
& \text { ‘...to the deed which happened.' }
\end{aligned}
$$

We can capture this by simply stating that Force lenites the next segment. The derivation is as follows:

$$
\text { Force }[\text { Rel }] * \mathrm{PV} * \mathrm{~V} \rightarrow[\mathrm{PV}+\text { Force }[\text { Rel }]] * \mathrm{~V}
$$

Force will clause lenition on the initial segment of the verb. Crucially, we also predict that the verb will be marked as conjunct here rather than as relative, since Force[Rel] is not in the correct position to condition allomorphy. Furthermore, we predict lack of lenition wherever the simple verb bears relative marking. This prediction is correct for all the Wurtzburg and Milan glosses (see (105) above), although the system breaks down in later writings, where we find sporadic lenition of relative inflecting verbs.

The analysis also extends to cases where certain particles in the C-system take relative clauses. An interesting case is $a$, meaning 'that which'. This particle nasalizes the following segment, but occurs with a relative clause (the phonological effect of nasalization of voiceless consonants is simply to voice them; this is not marked in the orthography). The following examples show the nasalization (bolded) occurring at the start of a simple verb, with relative marking on the verb:

$$
\begin{aligned}
& \text { a césme } \\
& \text { that-which suffer-[1P.R.PRES] } \\
& \text { 'that which we suffer' }
\end{aligned}
$$

$$
\mathrm{Ni} \text { tabeir díre as a n-gatass. }
$$

Neg PV-give-[3S.C.PRES] fine from that-which steal-[3s.R.PRES]

'He does not give a fine for that which he steals.'

(Ir. Recht $22 \S 24^{3}$ )

On our account, this follows if $a$ is in the specifier of Force[Rel]. Force[Rel] Locally Dislocates to $\mathrm{T}^{0}$, where it can act as a conditioner for allomorphy. The particle $a$ remains in place, now left adjacent to ForceP: 


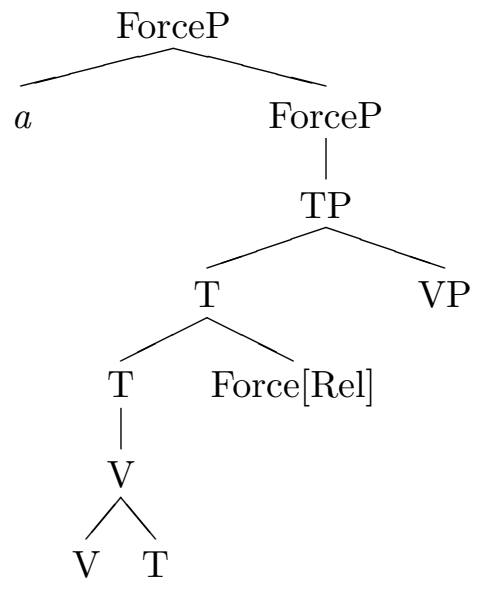

Now $a$ will nasalize the first segment of the verb, and the verb will appear in its relative form, the allomorphy being conditioned by Force[Rel]. The subject, being in a saperate phonological domain, is protected from lenition.

When $a$ is followed by a compound verb, we predict that it should nasalize the first element of the preverb, lenite the first segment of the remainder of the verb, and that conjunct inflection should appear on the verb. This follows from simply replacing V with PV in our schematic structure and applying the same processes of Local Dislocation:

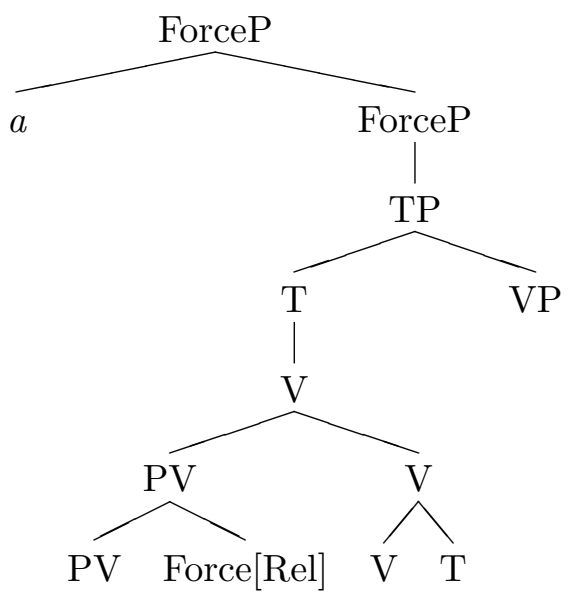

This is exactly correct. In the following example, the unlenited verb form is fiadar, where lenition has deleted the initial segment. The preverb is nasalized, as predicted:

$$
\begin{aligned}
& \text {... a n-ad íadar. } \\
& \text {... that-which PV declare-[3s.c.pres.pass] } \\
& \text { '...that which is declared.' }
\end{aligned}
$$

The system also correctly interacts with the syntax of wh-movement in Old Irish (again, see Newton 2002). There are two strategies for wh-movement in the language: one involves a stressed element followed by a relative form, and the other involves an apparent conjunct particle:

$$
\begin{array}{ll}
\text { Cía rannas dúib? } & \\
\text { who divide-[3s.R.PRES] for-you }
\end{array}
$$


a n-nad fetatar cía luid.

while Neg know-[3P.C.PRES] where go-[3s.C.PAST]

'While they didn't know where she went.'

(Imram Brain I 17.31)

On the account developed here, (114) must involve a wh-XP higher than Force, so that Force cliticizes to the verb triggering relative inflection. This might seem puzzling, given that Rizzi's (1997) system places wh-elements in Focus, which is lower than Force:

$$
[\text { ForceP Force }[\text { TopicP }[\text { FocusP } \text { WH Focus ... }
$$

However, there is good evidence that this kind of wh-construction is actually best analysed as a concealed cleft construction (see Adger and Ramchand 2005 for detailed evidence from Scottish Gaelic, one of the descendant languages of Old Irish, that this is still the case). Most tellingly, the third singular of the copula is not expressed in a wh-question in general:

$$
\begin{aligned}
& \text { cí hé? } \\
& \text { who he } \\
& \text { 'Who is he?' }
\end{aligned}
$$

Compare this with the following non-wh examples:

$$
\begin{aligned}
& \text { Is ed tobchétal nime in torainn. } \\
& \text { Cop it trumpeting heaven-[GEN] the thunder } \\
& \text { 'The thunder is the trumpet-song of heaven.' } \\
& \text { Is hé día as éola indium-sa. } \\
& \text { Cop he God that-cop-rel knowing in-me-[EMPH] } \\
& \text { 'It is god who is knowing in me.' }
\end{aligned}
$$

As in the modern languages, these clefts are used to construct nominal predications. It appears then, that there is a copula in the wh-question in (117), which has been deleted.

Given this evidence for copula deletion, we can treat our example in (117) as a concealed cleft, with a null copula and a relative clause:

$$
\begin{aligned}
& \text { [cía] Cop Force[Rel] rannas dúib } \\
& \text { who divide-[3s.R.PRES] for-you } \\
& \text { 'Who (is it that) divides for you?' }
\end{aligned}
$$

Force[Rel] inverts over the verb, giving rise to relative inflection, as described above, accounting for why we find relative inflection in these constructions as opposed to conjunct.

What of the second type of wh-question? In these cases, it appears that the wh-element indeed sits in its expected position:

$$
\begin{aligned}
& {[\text { ForceP } \text { Force }[\text { FocusP } \text { cía Focus luid }} \\
& \text { where go-[3s.C.PAST] }
\end{aligned}
$$

Force inverts with this $\mathrm{X}^{0}$ element, giving the following structure:

$$
[\text { ForceP }[\text { FocusP }[\text { cía+Force }] \text { Focus luid }
$$


Since Force is not in the right position to condition allomorphy of inflection, we correctly predict conjunct inflection. We also predict that verbal stress should immediately follow the wh-word in these constructions, as should enclitic pronouns. This is because the wh-word effectively becomes $\mathrm{X}$ in our original schema $(\mathrm{X} .[\mathrm{Y}+\mathrm{W}+\mathrm{Z}])$. Both of these predictions are correct:

Cía BEIR?

who carry-[3S.C.PRES]

'Who carries?'

Cich -ib foruireth?

what you PV-do-[3S.C.PERF]

'What has been done to you?'

Furthermore, we predict that this second strategy should only be possible where the wh-expression is an $\mathrm{X}^{0}$, while the previous strategy should allow XP wh-expressions.

What we see, then, is that the approach defended here makes a wide ranging collection of intricate predictions about allomorphy in the Old Irish verb. This allomorphy depends on the position of the Force morpheme.

This approach has an interesting theoretical ramification. Since allomorphy is the result of context sensitive vocabulary insertion, it follows that the movement process here must precede vocabulary insertion, or else it could not condition allomorphy. However, we have seen that this process bears the hallmarks of Local Dislocation, rather than Lowering, in that it targets the next adjacent $\mathrm{X}^{0}$ element, rather than the head of the complement. A Lowering analysis would not allow us to capture cases where Force cliticizes to the initial preverb of a compound verb. To the extent that this analysis is correct, it appears that Local Dislocation and Lowering both precede Vocabulary Insertion, contra Embick and Noyer (2001). ${ }^{15}$

\subsection{Syntax}

The final peculiarity of the Old Irish verb which we will tackle is the positioning of pronominal clitics. These appear in second position, after either the conjunct particles or the preverb, or the absolute marked verb.

We can understand this distribution in terms of the Rizzian structure of the C-domain. Recall that Rizzi (1997) proposed the following structure:

$$
\left[{ } _ { \text { ForceP } } \text { Force } \left[_ { \text { TopP } } \text { Top } \left[\text { FocusP } \text { Focus } \left[_ { \text { TopP } } \text { Top } \left[_ { \text { FinP } } \text { Fin } \left[{ }_{T P} \mathrm{~T} \ldots\right.\right.\right.\right.\right.\right.
$$

We have seen that the Focus position is activated in wh-questions. Nothing can intervene between the wh-element in a conjunct wh-question and the verb, which I take as evidence that the lower Top projection is not active in Old Irish. I will continue to assume that the verb is in $\mathrm{T}$ and that Fin is absent (but see the discussion in footnotes 13 and 15).

However, the higher Top projection, which in Rizzi's system marks old information, is a plausible position for object pronouns (see also Roberts 2005 who adopts the same view). Let us assume then that object pronouns in Old Irish obligatorily topicalize in the syntax:

$$
\text { Force }\left[{ }_{T o p P} \text { pronoun }[T P[\mathrm{~V}+\mathrm{T}] \ldots\langle\text { pronoun }\rangle \ldots\right.
$$

Now, let us take the pronoun, just like Force, to be an $\mathrm{X}^{0}$ enclitic, whose placement also derives from Local Dislocation in the Spellout component. There are two possibilities: Force lowers to the pronoun, and then the newly created complex pronoun lowers to the verb; or the pronoun lowers 
to the verb, creating a complex verb, which Force then lowers to. In either case, the pronoun will linearly precede Force. There appears to be some empirical evidence favoring the former position, which I will outline below. Anticipating this, I'll take a simple verb with a suffixed pronoun to have the following structure, with the pronoun projecting a $\mathrm{D}^{0}$ :

$$
[[\mathrm{V}+\mathrm{T}]+[D \text { pronoun }+ \text { Force }]]
$$

This ordering appears to be correct. In the presence of a suffixed pronoun, the verb inflection is forced to be absolute (that is, it cannot be conjunct or relative) and furthermore, deponent verbs take active inflection just in this case. That is, there is variation in the realisation of $\mathrm{T}$ for deponent verbs which is conditioned by the presence of a suffixed pronoun.

$$
\begin{aligned}
& \text { a. bertaigidir 'shakes' (deponent ending) } \\
& \text { b. bertaigth-ius 'shakes them' (active ending with loss of deponent }-r \text { ) }
\end{aligned}
$$

These properties suggest that allomorphy of $\mathrm{T}$ is triggered by the suffixed pronoun, which is, of course exactly what this structure predicts. The fact that the pronoun is closer to $\mathrm{T}$ than Force explains why, even with Force[Rel], we find absolute inflection. The schematic vocabulary item looks as follows:

$$
\text { / absolute / } \leftrightarrow \mathrm{T} / \ldots \text { pronoun }
$$

This will ensure that absolute appears to the left of a suffixed pronoun, irrespective of whether the verb is relative or deponent. Furthermore, in the phonological component, the suffixed pronoun is treated as part of the prosodic word headed by the verb, so that processes of syncope and final devoicing are conditioned by the presence of the pronoun. If Force were to be positioned before the pronoun, then extra statements would have to be made in the prosodic component to ensure that the prosodic boundary engendered by Force still allowed prosodic incorporation of the pronoun into the verb. This is unnecessary given the structure proposed here. This accounts for the positioning and allomorphy behavior of suffixed pronouns.

For cases where there is a preverb we have the following structure after lowering:

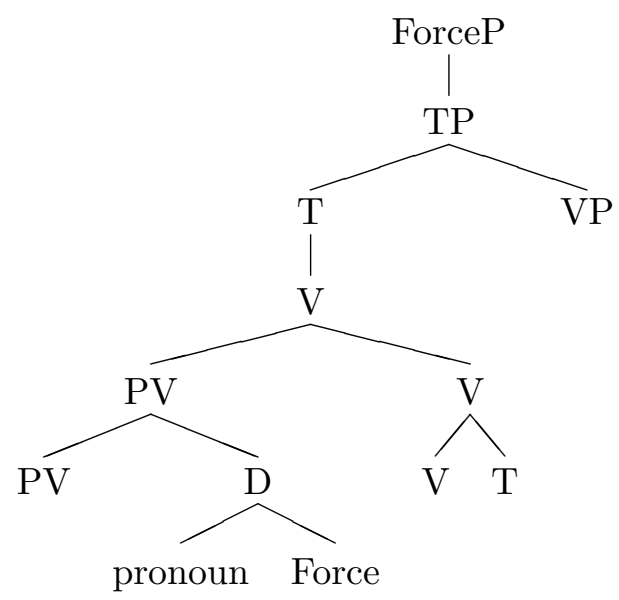

This approach makes some correct predictions about the interaction of preverbs and pronouns. Since Force is adjoined to the pronoun, the projection of the pronoun (D) is adjacent to the next preverb (or verb). This predicts that it can be the pronoun that triggers mutation, rather than 
Force. This is correct. Each pronominal form has its own idiosyncratic mutation effect (e.g first and second singular lenite, while third singular masculine nasalizes). This effect applies to the first segment of the verbal complex after the pronoun:

(131) ma immi $\mathrm{m}$ thabarthar,

if PV 1s surround-[3S.C.PRES.DEP]

'If I am surrounded,'

(Ml. $\left.41^{c} 2\right)$

Du s n-gni.

PV 3SF make-[3S.C.PRES]

'He makes it(fem).'

(Ml. 29 3 )

In (131), the first singular object pronoun lenites the following verb, while in (132) the third singular feminine object pronoun nasalizes the following verb.

This is the evidence that suggests that Force Locally Dislocates to the pronoun, which itself then Locally Dislocates. If the pronoun were to dislocate first, adjoining to the preverb, and then Force were to further adjoin, Force would be hierarchically superior, and might be expected to exert its own mutation, overriding that of the pronouns. This, however, does not happen. The same pronominal mutation effect is shown below when the pronoun suffixes to negation, rather than to a preverb:

Ní m charat-sa.

Neg me love-[3P.C.PRES] -EMPH

'They do not love me.'

$\left(\mathrm{Wb} .5^{c} 6\right)$

(134) Ní n-aithgéuin.

Neg recognize-3S.C.PAST]

'He did not recognize him.'

This perspective on the syntax of cliticization in Old Irish also gives us some insight into two archaic constructions found mainly in Old Irish verse: tmesis and Bergin's Construction. Tmesis involves the separation of the conjunct particle or preverb in $\mathrm{C}$ from the rest of the verbal complex by not just a clitic, but by phrasal elements, bolded here (see, e.g., McCloskey (1978):

$$
\begin{aligned}
& \text { ónd ríg do rea ruasat } \\
& \text { from-the king PV spaces PV-PV-create-[3s.C.PAST] } \\
& \text { 'From the king who has created (celestial) spaces.' } \\
& \text { for -don itge Brigte bet } \\
& \text { PV us prayers Brigit-[GEN] be-[3P.C.PRES.SUBJ] } \\
& \text { 'On us be Brigit's prayers.' }
\end{aligned}
$$$$
\text { (Imram Brain 48) }
$$

Bergin's construction (see Bergin 1938, Doherty 2000 and references therein) involves cases where the verb is not initial and bears conjunct inflection:

(137) ceso [femmuin mbolgaig] mbung

although seaweed blistered reap-[1s.C.PRES]]

'although I reap blistered seaweed'

(Bergin 1938: 197)

$$
\text { [Aicher Artt Mug Muad] marb máru }
$$

Aicher Artt Mug Muad kill-[3s.C.PAST] great-men

'Mug-Airtt, fierce, renowned slew great men.'

((Carney 1977-79): 433) 
In both of these constructions we find conjunct inflection. Both are stylistically poetic, and I take them to be formed via an alteration of the normal patterns of Old Irish syntax.

Doherty (2000) argues that Bergin's construction is best analysed as a type of V2, and to a certain extent I concur. Like Doherty, I assume that the preverbal elements are some kind of topic. Given the syntactic framework adopted here, they are therefore placed in TopP. What, then, happens to Force, which should encliticise to the first $\mathrm{X}^{0}$ ? My suggestion is that Force cannot cliticize to an element inside the Topic, because the Topic is a phonologically complete phrase, but Force must cliticise to a morphological word. ${ }^{16}$ It follows that DP topics are usually ruled out in the language, since their presence would mean that Force could never be licensed. However, poetic registers allow such topics via exceptional grammatical operations, leading to these constructions. One such operation is simply the deletion of Force. This would mean that (139), has the following structure:

$$
\text { Force }[\text { TopP flood-tide of waves }[T P \text { PV-V }
$$

Recall that in Rizzi's system Topics can be iterated, this gives rise to examples like the following, which do not appear to be V2, contra Doherty:

$$
\begin{aligned}
& \text { [mortlaidi móra] [di dóenib] dingbatar } \\
& \text { [plagues great] [from people] PV-keep-[3P.C.PRES.PASS] } \\
& \text { 'Great plagues from people are kept.' }
\end{aligned}
$$

(Bergin 1938: 202)

In the system outlined here, these cases are expected, as Topics may iterate. Note that we also correctly predict the conjunct inflection found in Bergin's Constructions. Since Force is deleted, it cannot be present to condition allomorphy, leaving conjunct as the only possible inflection.

The alternative to deleting Force, when there is a full DP topic in TopP is to anomalously treat such a Topic as a clitic and Locally Dislocate it, even though it is a phrase. This gives us:

$$
\text { Force }^{*} \mathrm{DP} * \mathrm{PV} * \mathrm{~V}+\mathrm{T} \rightarrow[\mathrm{PV}+\mathrm{DP}+\text { Force }] * \mathrm{~V}+\mathrm{T}
$$

This analysis gives the following kind of structure for tmesis:

$$
\begin{aligned}
& \text { ónd ríg }[\text { do }+[\text { rea+Force }]] \text { ruasat } \\
& \text { from-the king PV spaces PV-PV-create-[3s.C.PAST] } \\
& \text { 'From the king who has created (celestial) spaces.' } \\
& {[[[\text { for }+ \text { don }]+[[\text { itge Brigte }]+\text { Force }] \text { bet }} \\
& \mathrm{PV} \text { us prayers Brigit-[GEN] be-[3P.C.PREs.SUBJ] } \\
& \text { 'On us be Brigit's prayers.' }
\end{aligned}
$$

These speculations about the two poetic constructions must remain tentative. It is merely my intention to show how these constructions can be reconciled with the kind of analysis of the prosody, morphology and clitic-placement facts with which this article has been mainly concerned. 


\section{Conclusions}

This article has argued for the necessity of post-syntactic but pre-prosodic movement operations, of the sort that have been proposed by Marantz (1988), and more recently by Embick and Noyer (2001). The argument is that the intricacies of the Old Irish verbal complex are not amenable to a syntactic analysis, but that they do involve limited transposition of elements. These transpositions feed morphological and prosodic operations, such as Vocabulary Insertion (for allomorphy) and prosodic phrasing, so they must be post-syntactic but pre-prosodic.

\section{Notes}

${ }^{1}$ Many thanks to no less than five anonymous referees, who have helped shape this paper, to audiences at Essex, Cambridge, University College London and Stuttgart. Many thanks also to Daniel Harbour.

${ }^{2}$ Annotations to the Old Irish examples are those standard in the philological literature (see Thurneysen 1975, itself abbreviated as GOI (Grammar of Old Irish)). Wb. signifies the Wurtzburg glosses and Ml. the Milan glosses (both ninth century). I have also taken data from secondary sources such as McCone (1997).

${ }^{3}$ Thanks to an anonymous referee for this elegant formulation of the problem.

${ }^{4}$ Certain preverbs elide vowels so that they consist only of an unstressable consonant. In such cases the stress falls on the next preverb, which is still the first syllable. McCone (1997) gives the contrast between do-AIR-n-gar, 'he promises' and ni-T-AIR-n-gar, 'he does not promise', where do is reduced to $t$ and stress falls on the vowel of the second preverb.

${ }^{5}$ This stress pattern is known as deuterotonic stress, and contrasts with prototonic stress, where the compound verb has stress on the first preverb, as in (23) and (24).

${ }^{6}$ Sometimes a verb displays no absolute/conjunct contrast in particular parts of the paradigm. This is true, for example, in the imperfect indicative. One might think then, that a verb like celebartis in (15) is neither conjunct nor absolute. However, given that in the imperfect such verbs in matrix initial position are always preceded by a particle no unless they are themselves compound verbs, the simplest approach is to say that they are in fact always conjunct. This is the solution adopted by Thurneysen (1975), who characterises no as a conjunct particle.

${ }^{7}$ Since the conjunct particles are all plausibly complementizers, we might want to strengthen this generalization to the claim that conjunct inflection appears whenever there is a complementizer (see Doherty 2000, Roberts 2005 for such a claim). However, the situation here is a little more complicated, because, as we have seen, there are other ways of embedding verbs than with a complementizer. The nasalizing strategy we saw above (10) occurs with verbs which have another special inflectional paradigm usually associated with relative clauses. There are also certain complementizers which are followed by verbs which have absolute inflection:

$$
\begin{aligned}
& \text { má beid ní di rúnaib do-théi ar menmuin ind fir } \\
& \text { if be-[3S.A.PRES.SUBJ] anything of mysteries go-3s.SUBJ before mind the man } \\
& \text { 'If it might be that any of the mysteries should come before the mind of man ...' } \\
& \text { (Wb. } \left.13^{a} 12\right)
\end{aligned}
$$

Thanks to an anonymous reviewer for pointing this out and providing the example. See section 4.4 for analysis.

${ }^{8}$ Holloway-King (1997) provides an interesting alternative: the relativization of the ECP pays attention to the clitic status of the heads, rather than their A/Astatus; only non-clitic element may 
raise across a clitic elements. Clearly this option will not do here, since the preverb must raise across both clitics and non-clitics on CHPs analysis.

${ }^{9}$ This set of conclusions also holds for an alternative, which alalyses the preverb movement in an initial compound verb as XP movement, perhaps from a remnant VP in the specifier of TP. Such an alternative would not require excorporation, but the same arguments developed here would apply, mutatis mutandis.

${ }^{10}$ At the input to Local Dislocation, $\mathrm{T}$ and $\mathrm{V}$ are both subwords, since they are terminal $\mathrm{X}^{0} \mathrm{~s}$. Local Dislocation of $\mathrm{T}$ to $\mathrm{V}$ then creates a complex subword, which itself is the target of the next Local Dislocation operation.

${ }^{11} \mathrm{I}$ am not wedded to this OT implementation of the analysis here, although it does make use of well motivated constraints. An alternative is a rule which simply says that the lexical stress of a word is realized to the left of that word, but that it cannot cross Force.

${ }^{12}$ The only case of enclisis to $\mathrm{V}$ are a set of emphatic particles which presumably encliticise to $\mathrm{T}$ before prosodic phrasing.

${ }^{13}$ We could alternatively move the verb to Fin, which is then deleted in the morphology, as it bears just unmarked feature values. See footnote 15 .

${ }^{14}$ Lenition of relative clauses also occurs with object extraction, however, it is not obligatory in this case, and alternates with nasalization. Nasalization itself is also found with adjunct relativisation. I leave the syntax of these nasalizing relatives for another occasion.

15 There is a question of how this operation of Local Dislocation interacts with heads whose final phonological content is null. It seems that we want to ignore such heads in applying Local Dislocation, which leads to an apparently paradoxical situation that we need to know that a head is null for the purposes of Local Dislocation before accessing the phonological content of that head. I suggest that the solution to this problem is that functional heads which bear only default features are either not present in the syntax at all, and their interpretation is filled in at the Conceptual/Intentional Interface, or that such heads are deleted in the morphological component at the point of Morphological Labeling. It is for this reason that these heads lack a phonological expression.

${ }^{16}$ One might ask why Force cannot simply cliticize to the first element of the DP. Following (Uriagereka 1999), I take DP specifiers to have already undergone Spellout by the time that the next higher head is Merged. It follows that Local Dislocation cannot target the interior of the DP.

\section{References}

Adger, David. 1996. Agreement, aspect and measure phrases in Scottish Gaelic. In Robert Borsley and Ian Roberts, eds., The Syntax of the Celtic Languages, 200-222, Cambridge: Cambridge University Press.

Adger, David. 2000. V1 phenomena and the syntax prosody interface. In Roger Billerey and Brook Danielle Lillehaugen, eds., Proceedings of the West Coast Conference on Formal Linguistics (WCCFL) 19, 1-14, Somerville, MA.: Cascadilla Press.

Adger, David and Ramchand, Gillian. 2005. Move and Merge: Wh-dependencies revisited. Linguistic Inquiry 36:161-194.

Anderson, Stephen. 1993. Wackernagel's revenge: clitics, morphology and the syntax of second position. Language 69:68-98.

Anderson, Stephen and Chung, Sandra. 1977. On grammatical relations and clause structure in verb-initial languages. In Peter Cole and Jerry Sadock, eds., Grammatical relations, 
Syntax and semantics 8, 1-25, New York: Academic Press.

Bergin, Osborn. 1938. On the syntax fo the verb in Old Irish. Ériu 12:197-214.

Bobaljik, Jonathan and Carnie, Andrew. 1996. A minimalist approach to some problems of Irish word order. In Robert Borsley and Ian Roberts, eds., The Syntax of the Celtic Languages, 223-240, Cambridge: Cambridge University Press.

Borsley, Robert, Rivero, Maria-Louisa, and Stephens, Janig. 1996. Long Head Movement in Breton. In Robert Borsley and Ian Roberts, eds., The Syntax of the Celtic Languages, 53-74, Cambridge: Cambridge University Press.

Breatnach, Liam. 1977. The suffixed pronouns in Early Irish. Celtica 12:75-107.

Carney, James. 1977-79. Aspects of Archaic Irish. Éigse 17:417-435.

Carnie, Andrew and Guilfoyle, Eithne. 2000. The Syntax of VSO languages. New York: Oxford University Press.

Carnie, Andrew, Harley, Heidi, and Pyatt, Elizabeth. 1995. The resurrection: Raising to Comp? some evidence from Old Irish. In Proceedings of the Fifth Annual Conference of the Formal Linguistics Society of Mid-America, 85-100, FLSMA.

Carnie, Andrew, Harley, Heidi, and Pyatt, Elizabeth. 2000. VSO order as raising out of IP: Some evidence from Old Irish. In Andrew Carnie and Eithne Guilfoyle, eds., The Syntax of Verb Initial Languages, 39-59, New York: Oxford University Press.

Chomsky, Noam. 1993. A minimalist program for linguistic theory. In Kenneth Hale and Samuel Keyser, eds., The view from Building 20, 1-52, Cambridge, MA: MIT Press.

Chomsky, Noam. 1995. The Minimalist Program. Cambridge, MA: MIT Press.

Chomsky, Noam. 2000. Minimalist inquiries: the framework. In R. Martin, D. Michaels, and Juan Uriagereka, eds., Step by Step: Essays on Minimalist syntax in honour of Howard Lasnik, 89-115, Cambridge, MA: MIT Press.

Chomsky, Noam. 2001. Derivation by phase. In Michael Kenstowicz, ed., Ken Hale: A Life in Language, 1-52, Cambridge, MA: MIT Press.

Doherty, Cathal. 2000. Residual verb second in Early Irish: On the nature of Bergin's constructions. Diachronica 17:5-38.

Duffield, Nigel. 1995. Particles and Projections in Irish Syntax. Dordrecht: Kluwer Academic Publishers.

Embick, David and Noyer, Rolf. 2001. Movement operations after syntax. Linguistic Inquiry 32:555-595.

Green, Antony Dubach. 1997. The prosodic structure of Irish, Scots Gaelic and Manx. Ph.D. thesis, Cornell University.

Hale, Ken and Keyser, Samuel J. 1993. On argument structure and the lexical expression of syntactic relations. In Ken Hale and Samuel J. Keyser, eds., The View from Building 20, 53-109, Cambridge, Massachusetts: MIT Press.

Halpern, Aaron. 1995. Topics in the Placement and Morphology of Clitics. Stanford, CA: CSLI.

Holloway-King, Tracy. 1997. The prosodic status of A and A'-heads in Slavic. In Proceedings of NELS 27, 253-249, University of Massachusetts at Amherst: GLSA.

Isaac, G.R. 1993. Issues in the reconstruction and analysis of Insular Celtic syntax and phonology. Ériu 44:1-32. 
Jeffers, Richard J. 1978. Old Irish verbal nouns. Ériu 29:1-13.

Larson, Richard. 1987. On the double object construction. Linguistic Inquiry 19:33-91.

Marantz, Alec. 1988. Clitics, Morphological Merger, and the mapping to Phonological Structure. In Michael Hammond and Michael Noonan, eds., Theoretical Morphology: Approaches in Modern Linguistics, 253-270, San Diego: Academic Press.

McCloskey, James. 1978. Stress and syntax in Old Irish compound verbs. In Susan F. Schmerling and Carlota S. Smith, eds., Texas Linguistic Forum, 58-71, University of Texas at Austin: Department of Linguistics.

McCloskey, James. 1983. A VP in a VSO language? In Gerald Gazdar, Ewan Klein, and Geoff Pullum, eds., Order Concord and Constituency, 9-55, Dordrecht: Foris.

McCloskey, James. 1991. Clause structure, ellipsis and proper government in Irish. Lingua 85:259-302.

McCloskey, James. 1996. On the scope of verb movement in Irish. Natural Language and Linguistic Theory 14:47-104.

McCone, Kim. 1979. Pretonic preverbs and the absolute verbal endings in Old Irish. Ériu 30:1-34.

McCone, Kim. 1982. Further to Absolute and Conjunct. Ériu 33:1-30.

McCone, Kim. 1997. The Early Irish Verb. Maynooth: An Sagart.

Newton, Glenda. 2002. The double system of verbal inflection in Old Irish: A minimalist analysis, unpublished MPhil thesis, University of Cambridge, Cambridge, U.K.

Ó hUiginn, Ruairí. 1998. Complementation in Early Irish: the verba dicendi. Ériu 49:121-148.

Pesetsky, David. 1995. Zero Syntax: Experiencers and Cascades. Cambridge, MA: MIT Press.

Poletto, Cecilia. 2000. The Higher Functional Field: Evidence from Northern Italian Dialects. Oxford: Oxford University Press.

Pollock, Jean-Yves. 1989. Verb movement, Universal Grammar and the structure of IP. Linguistic Inquiry 20:365-424.

Ramchand, Gillian. 1997. Aspect and Predication:The Semantics of Argument Structure. Oxford: Oxford University Press.

Rivero, Maria-Louisa. 1991. Long Head Movement and negation: Serbo-Croatian vs. Slovak and Czech. The Linguistic Review 8:319-351.

Rivero, Maria-Louisa. 1994. Clause structure and V-movement in the languages of the Balkans. Natural Language and Linguistic Theory 12:63-120.

Rivero, Maria-Louisa. 2000. Finiteness and second position in Long Head Movement languages. In Robert Borsley, ed., The Nature and Function of Syntactic Categories, 295-323, New York: Academic Press.

Rizzi, Luigi. 1997. The fine structure of the left periphery. In Liliane Haegeman, ed., Elements of Grammar: Handbook of Generative Syntax, 281-337, Dordrecht: Kluwer.

Rizzi, Luigi and Roberts, Ian. 1989. Complex inversion in French. Probus 1:1-39.

Roberts, Ian. 1994. Two types of head movement in Romance. In David Lightfoot and Norbert Hornstein, eds., Verb Movement, 207-242, Cambridge: Cambridge University Press. 
Roberts, Ian. 2005. Principles and Parameters in a VSO language. Oxford and New York: Oxford University Press.

Roberts, Taylor. 2000. Clitics and agreement. Ph.D. thesis, MIT.

Selkirk, Elisabeth. 1986. On derived domains in sentence phonology. Phonology 3:371-405.

Selkirk, Elisabeth. 1995. The prosodic structure of function words. In University of Massachusetts Occasional Papers, 439-469, Amherst, MA: GLSA.

Sproat, Richard. 1985. Welsh syntax and VSO structure. Natural Language and Linguistic Theory 3:173-216.

Starke, Michal. 2004. On the inexistence of specifiers and the nature of heads. In Adriana Belletti, ed., Structures and Beyond, 252-268, Oxford and New York: Oxford University Press.

Szendroi, Kriszta. 2001. Focus and the syntax-phonology interface. Ph.D. thesis, University College London.

Thurneysen, Rudolf. 1975. A Grammar of Old Irish. Dublin: Dublin Institue for Advanced Studies.

Uriagereka, Juan. 1999. Multiple spellout. In Samuel David Epstein and Norbert Hormstein, eds., Working Minimalism, 251-282, Cambridge, MA: MIT Press.

Watkins, Calvert. 1963. Preliminaries to a Historical and Comparative syntax of the Old Irish verb. Celtica 6:1-49. 